IFN Working Paper No. 754, 2008

How Differences in Property Taxes within Cities Affect Urban Sprawl?

Yan Song and Yves Zenou 


\title{
How Differences in Property Taxes within Cities Affect Urban Sprawl?*
}

\author{
Yan Song $^{\dagger} \quad$ Yves Zenou
}

June 12, 2008

\begin{abstract}
This article attempts a formal analysis of the connection between the differentiated property tax rates within urban areas and urban spatial pattern in U.S. cities. We first develop a duocentric-city model where the Central Business District (CBD) is located at the origin while the Suburban Business District (SBD) is at the other end of the city. We show that the ratio between the property tax in the suburbs and in the center has an ambiguous impact on the size of the city. We then test this model empirically to determine this sign by using a dataset of effective property tax rates we developed using GIS techniques for central cities and suburbs in 445 urbanized areas. The empirical analysis estimates the link between these two variables by controlling for variables such as population, income, agricultural rent, commuting cost, climate, crime, and employment structure. Results from the empirical analyses suggest that a lower property tax rate in the suburbs in comparison to the central city is associated with more expansive urban growth and greater level of decentralization of population and employment.
\end{abstract}

J.E.L. Classification: H3, H71, R14

Keywords: central city, suburbs, urban sprawl, urban decentralization, differentiated property tax.

${ }^{*}$ We are grateful to the editor Marlon Boarnet, two anonymous referees, and Jan Brueckner for very helpful comments. We are also grateful to the Lincoln Institute of Land Policy for financial support. Yves Zenou also thanks the Bank of Sweden Tercentenary Foundation for financial support.

$\dagger$ University of North Carolina at Chapel Hill, USA. E-mail: ys@email.unc.edu.

${ }_{\ddagger}^{\ddagger}$ Stockholm University and Research Institute of Industrial Economics. E-mail: yves.zenou@ne.su.se. 


\section{Introduction}

Many studies have examined the determinants and consequences of urban development patterns in the urban economics, urban policy, and planning literature. Much of this literature has focused on both urban sprawl and urban decentralization in the U.S. cities. Urban sprawl is a pejorative term that connotes the undesirable features of contemporary urban development pattern. Such features include, for example, low density and separated land uses, automobile orientation, and unsightliness. Urban decentralization refers to the movement of population and businesses away from the established city center towards the urban fringe. Urban decentralization depicts two waves of urban sprawl: decentralization of both population and employment. In the first wave of decentralization, population moved to the suburbs since the late 19th century. By as late as 1960, however, most jobs (63 percent of jobs) were still in the central city while 51 percent of population lived in suburbs. In the subsequent second wave of decentralization, jobs decentralized too. By 2000, people both live and work in the suburbs. Across regions, the share of employment within 3 miles of the city center is rarely more than 19 percent (Glaeser and Kahn, 2001).

The urban development pattern in most U.S. cities, featured by urban sprawl and both population and employment decentralization, has been criticized for consuming a large amount of land, demanding huge investment on transportation and facilities, worsening social inequality, threatening the environment and so forth. ${ }^{1}$ The recent U.S. 2000 census data provided considerable new evidence on the problem of urban sprawl. With these data, researchers have shown that urban areas continue to grow faster than their populations, causing urban densities to fall. These trends suggest that the development pattern in most of the U.S. cities is getting more unsustainable.

Previous studies have sought to identify the determinants of urban sprawl. Brueckner and Fansler (1983) and McGrath (2005) place the topic of urban sprawl within standard urban economic theoretical framework. Both studies have estimated the equation for urban spatial size derived from the standard monocentric urban model, in which urban land area is regressed on a set of determinants such as population, income, transportation costs, and agricultural land values. They find that increased population, income, and agricultural land values nearby and lower transportation costs are associated with more urban sprawl. In a recent study by Burchfield et al. (2006), ground water availability, temperate climate, rugged terrain, decentralized employment, early public transport infrastructure, uncertainty

\footnotetext{
${ }^{1}$ For overviews on urban sprawl issues, see Brueckner (2000), Glaeser and Kahn (2004), Nechyba and Walsh (2004).
} 
about metropolitan growth and unincorporated land in the urban fringe are also found to increase sprawl. Concomitantly, research on what causes the cities to decentralize, both in population and employment, remains active. A substantial literature focuses on explanation of the postwar decentralization of cities using both qualitative discussions and quantitative tests of models of urban spatial economy. It is commonly believed that transportation costs, income increase, housing costs, metropolitan growth, household structure, racial transition, and crime rate are the causal factors that account for suburbanization (Edmonston and Guterbock, 1984; Rappaport, 2005). In a more recent study, Baum-Snow (2007) assesses the extent to which the construction of new limited access highways has contributed to central city population decline and he concludes that one new highway passing through a central city reduces its population by about 18 percent. Glaeser and Kahn (2001) establish several connections between industrial mix, human capital, land costs, transportation costs and employment decentralization. They find that cities that specialize in services are more centralized while cities that specialize in manufacturing tend to sprawl since manufacturing, incurring cheaper transportation costs than services, is more land intensive. Furthermore, employment in cities with more idea-intensive industries is more likely to be centralized, and employment in cities where the workforce demands more suburban lifestyles is more likely to suburbanize. For a comprehensive review on quantitative analysis of urban development pattern, please refer to Clifton et al. (2008).

Additional studies have suggested that the property tax may influence urban development pattern. The long-standing debate on land taxation and its virtues (George, 1879; Skaburskis and Tomalty, 1997) reveals that the property tax might be one of the potential causes of urban sprawl. The property tax can be viewed as a tax levied at equal rates on both the land and capital embodied in structures while, in a pure land tax, the tax on capital (i.e., improvements) is set to zero. The literature (for example, Arnott and MacKinnon, 1977; Case and Grant, 1991; Oates and Schwab, 1997; Mills, 1998; and Brueckner and Kim, 2003) provides an abundance of arguments for how the property tax may influence land development. Brueckner and Kim (2003) were the first to provide a theoretical analysis that incorporates a land market to investigate the connection between urban spatial expansion and the property tax. In their equilibrium analysis, they found two countervailing effects of the property tax on the spatial size of cities. On the one hand, the improvement effect refers to the impact of the property tax in lowering the equilibrium level of improvements chosen by the developer. The lower level of improvements per acre implies a reduction in the intensity of land development and this lower density associated with property tax appears to encourage urban sprawl. On the other hand, the dwelling size effect operates through the 
property tax's impact on the consumer's choice of dwelling sizes. As the tax on land and structures is partly shifted forward to consumers, dwelling size decreases due to a higher cost of housing floor space. The reduction in dwelling size implies an increase in population density and thus, a decrease in the city's size or spatial extent. In Brueckner and Kim's full analysis, the net effect of the property tax on the spatial extent of a city is ambiguous. However, using a Constant Elasticity of Substitution (CES) utility function with an elasticity of substitution greater than or equal to one, Brueckner and Kim (2003) were able to show that the relationship between the property tax and urban sprawl is always negative.

Following this line of research, Song and Zenou (2006) develop a theoretical model in the same vein as Brueckner and Kim (2003) but with a log-linear utility function, which exhibits variable, rather than constant, elasticity of substitution but where the elasticity also exceeds one. The main feature of their utility function is that it has a zero income elasticity of housing demand but it allows us (contrary to the CES case) to have explicit closed-form solutions. They unambiguously show that increasing property taxes reduces urban scale.

However, the studies of Brueckner and Kim and Song and Zenou are limited since they does not differentiate property tax rates within urbanized areas while the variation of tax rates between the central city and the suburbs is a common feature in U.S. urban areas due to governance fragmentation. Indeed, differentiated tax rates within urbanized areas can affect the spread of the urban regions. The hypothesis is that if the property tax rate is higher in central city than in suburbs, more residential and business developments would be driven away to the suburbs. In other words, lower property tax rate in suburbs would induce developments and thus cause urban sprawl. This is an important but understudied issue and we attempt to examine the issue in the present paper. For that, we extend our previous research (Song and Zenou, 2006) by taking explicitly differentiated tax rates within an urban area into account.

In this paper, we first develop a duocentric urban model where residents pay different property taxes depending where they reside. There are two main areas: the central part of the city and the suburbs. Firms/developers enter in the market in one of the areas and decide their level of improvement. We characterize the equilibrium in this city and show that the ratio between the property tax in the suburbs and in the center has an ambiguous impact on the size of the city. We give a condition under which this impact is negative.

We then test empirically the main result of our model. We collect data on the property effective tax rates from various taxing jurisdictions and develop a sample of effective tax rates for 445 urbanized areas in the U.S. For each urbanized area, we further divide the area between the central city and the suburbs. 
The present paper contributes to the research on urban sprawl with its main results from the empirical analysis suggesting that a lower ratio of the property tax rate in the suburbs than in the center may be a determinant of urban sprawl and population and employment decentralization. The present paper also contributes to the theoretical literature on nonmonocentric cities (Fujita and Ogawa, 1980; Ogawa and Fujita, 1982; Fujita and Thisse, 2002) and more particularly on that of duocentric cities (Henderson and Mitra, 1996; Fujita, et al., 1997; Smith and Zenou, 1997; Brueckner and Zenou, 2003; Zenou, 2009). Indeed, in the latter, different aspects of duocentric cities have been investigated: formation of subcenters, urban unemployment, and spatial mismatch. Here we focus on the impact of differentiated property taxes on urban sprawl. To the best of our knowledge, this is the first paper that tackles this issue in a nonmonocentric framework.

\section{Theory}

We now develop our theoretical model in order to examine the connection between the property tax and urban sprawl in a duocentric city.

\subsection{The model}

City The city is duocentric, closed $^{2}$ and linear where the Central Business District (CBD hereafter) is located at the origin (zero) and the Suburban Business District (SBD hereafter) is located at the other end of the city, the city fringe $x_{f}$. All land is owned by absentee landlords.

The city is depicted in Figure 1. The area $a=c$ ( $c$ stands for the city-center) is between $x=0(\mathrm{CBD})$ to $x=\widetilde{x}$ and only individuals working in the CBD live there. The area $a=s$ ( $s$ stands for the suburbs) is between $x=\widetilde{x}$ and $x=x_{f}$ and only SBD-workers reside there.

$$
\text { [Insert Figure } 1 \text { here] }
$$

Firms (land developers) Firms are assumed to consume no space. We consider two types of firms: those located in the $\mathrm{CBD}$ or those in the SBD. For the area $a=c, s$, there is

\footnotetext{
${ }^{2}$ The assumption of a closed city model captures the fact that we are looking at a short-run equilibrium. Basically it says that the total population $N$ (but not the population of each part of the city $N_{c}$ or $N_{s}$ ) is fixed so that people cannot migrate either into the city or out of it. The closed-city is a good approximation when one focuses on small changes and on what happens in the next few years.
} 
a housing industry that has the following production function:

$$
Q_{a}=H\left(K_{a}, L_{a}\right)=2 \sqrt{K_{a} L_{a}}
$$

where $Q_{a}$ is the housing output in area $a$ and $L_{a}$ and $K_{a}$ are respectively land and capital (or nonland input) in area $a$. This function is increasing and concave in each of its arguments and has constant returns to scale, which implies that the production function can be written as:

$$
h\left(S_{a}\right)=\frac{Q_{a}}{L_{a}}=2 \sqrt{S_{a}}
$$

where $S_{a} \equiv K_{a} / L_{a}$ represents the capital per acre of land or improvements per acre in area $a$ and thus $h\left(S_{a}\right)$ is the housing output per acre of land in $a . S_{a}$ is also referred to as structural density (Brueckner, 1987) and is an index of the height of buildings. The function $h\left(S_{a}\right)$ defined by (2) is housing output per acre of land in area $a$, with $h^{\prime}\left(S_{a}\right)>0$ and $h^{\prime \prime}\left(S_{a}\right)<0$.

Denote by $\theta_{a}$ the property tax rate in area $a$. Then, each profit maximizing housing developer solves: ${ }^{3}$

$$
\max _{S_{a}}\left\{\pi_{a}=R_{H} 2 \sqrt{S_{a}}-\left(1+\theta_{a}\right)\left(R+r S_{a}\right)\right\} \quad \text { at each } x \in\left[0, x_{f}\right]
$$

where $\pi_{a}$ is the profit per acre of land in area $a, R_{H}$ is the rental price per unit of housing service $q, R$ is the rent per unit of land (land cost per acre) and $r$ the price of capital (or the cost per unit of $S_{a}$ ). The city fringe is denoted by $x_{f}$ and $x$ is the distance to the CBD.

Consumers/Workers There is a continuum of ex ante identical workers whose mass is fixed and equal to $N$. We assume that, even if workers are identical, the income in the CBD, $y_{c}$, is not necessarily equal to the income in the SBD, $y_{s}$. Indeed, as it is welldocumented, CBD-firms tend to be different than SBD-firms (see e.g. Glaeser and Kahn, 2001). In general, CBD-firms are those who need face-to-face communications and are more likely to belong to the service sector (banks, for example). On the contrary, SBD-firms need less face-to-face communications but more space. They are more likely to belong to the manufacturing sector. In our model, each firm is assumed to produce the same good at the same market price but firms in one center (the CBD), which can belong to a different sector, may have different productive capacities than those in the other center (the SBD). These differences can be due to different infrastructure and different access to other production

\footnotetext{
${ }^{3}$ Observe that it does not matter whether the developer or the urban resident pays the property tax $\theta_{a}$. The same results would emerge if the residents pay at a rate $\theta_{a}$, so that the gross-of-tax rent price is written $R_{H}\left(1+\theta_{a}\right)$. Then, the developer profit will just be $R_{H} h\left(S_{a}\right)-\left(R+r S_{a}\right)$, with no tax term showing up.
} 
factors than labor (Glaeser and Maré, 2001). These differences can also be due to different human capital externalities for workers (Duranton, 2006). All these theories predict that workers' marginal productivity will be different between the two centers and thus there will be income differences for identical workers between the CBD and SBD.

Among the $N$ workers, there are $N_{c}$ of them working in the CBD, earning an income of $y_{c}$, and $N_{s}$ employed in the SBD, earning $y_{s}$, so that

$$
N=N_{c}+N_{s}
$$

Each household contains one person. Each individual in area $a=c, s$ chooses $z_{a}$ and $q_{a}$ (where $z_{a}$ and $q_{a}$ are, respectively, the consumption of the composite good, whose price is taken as the numeraire, and the dwelling size in area $a$ ) that maximize his/her utility function under the budget constraint, i.e.

$$
\max _{z_{c}, q_{c}} U\left(z_{c}, q_{c}\right) \text { s.t. } z_{c}+R_{H} q_{c}=y_{c}-t x
$$

for CBD-workers and

$$
\max _{z_{s}, q_{s}} U\left(z_{s}, q_{s}\right) \text { s.t. } z_{s}+R_{H} q_{s}=y_{s}-t\left(x_{f}-x\right)
$$

for SBD-workers. Here, $t$ denotes the pecuniary commuting cost per unit of distance. As in Song and Zenou (2006), we assume a quasi-linear utility function, that is:

$$
U\left(z_{a}, q_{a}\right)=z_{a}+\log q_{a}
$$

In that case, solving (5) and (6) lead to:

$$
\begin{gathered}
q_{c}=q_{s}=q=\frac{1}{R_{H}} \\
z_{c}=y_{c}-t x-1 \\
z_{s}=y_{s}-t\left(x_{f}-x\right)-1
\end{gathered}
$$

The indirect utility functions can thus be written as:

$$
\begin{gathered}
u=y_{c}-t x-1-\log R_{H} \\
u=y_{s}-t\left(x_{f}-x\right)-1-\log R_{H}
\end{gathered}
$$


where $u$ is the utility level obtained by all individuals in the city (since all workers are identical and perfectly mobile, they must reach the same utility level in equilibrium), and the bid rent function is given by:

$$
\begin{gathered}
R_{H, c}(x, u)=\exp \left(y_{c}-t x-1-u\right) \\
R_{H, s}(x, u)=\exp \left[y_{s}-t\left(x_{f}-x\right)-1-u\right]
\end{gathered}
$$

Plugging the value of the bid rent in $q$ gives finally

$$
\begin{gathered}
q_{c}(x, u)=\exp \left(u-y_{c}+t x+1\right) \\
q_{s}(x, u)=\exp \left[u-y_{s}+t\left(x_{f}-x\right)+1\right]
\end{gathered}
$$

It is important to observe that, even though the housing consumption $q_{a}$ is not directly affected by income $y_{a}$ (see (8)), ${ }^{4}$ it is indirectly affected by income through the land rent (see (13)). Indeed, when income increases, the bid rent increases (see (12)) since people are richer. As a result, because housing is more costly, they consume less land and thus reduce their dwelling size. This seemingly counterintuitive result is due to the fact that we analyze the effect of $y_{a}$ on $q_{a}(x, u)$ holding $u$ constant.

\subsection{The equilibrium}

Plugging (12) in (3), the housing developer's program becomes

$$
\max _{S_{c}}\left\{\pi_{c}=2 \sqrt{S_{c}} \exp \left(y_{c}-t x-1-u\right)-\left(1+\theta_{c}\right)\left(R+r S_{c}\right)\right\}
$$

for firms in area $c$ at each $x \in[0, \widetilde{x}]$ and

$$
\max _{S_{s}}\left\{\pi_{s}=2 \sqrt{S_{s}} \exp \left[y_{s}-t\left(x_{f}-x\right)-1-u\right]-\left(1+\theta_{s}\right)\left(R+r S_{s}\right)\right\}
$$

for firms in area $s$ at each $x \in\left[\widetilde{x}, x_{f}\right]$. The first order conditions yield:

$$
\begin{gathered}
S_{c}=\frac{\exp \left[2\left(y_{c}-t x-1-u\right)\right]}{\left(1+\theta_{c}\right)^{2} r^{2}} \text { for } x \in[0, \widetilde{x}] \\
S_{s}=\frac{\exp \left[2\left(y_{s}-t\left(x_{f}-x\right)-1-u\right)\right]}{\left(1+\theta_{s}\right)^{2} r^{2}} \text { for } x \in\left[\widetilde{x}, x_{f}\right]
\end{gathered}
$$

and thus

$$
h\left(S_{c}\right)=2 \frac{\exp \left(y_{c}-t x-1-u\right)}{\left(1+\theta_{c}\right) r} \text { for } x \in[0, \widetilde{x}]
$$

\footnotetext{
${ }^{4}$ This is because of the log-linear nature of the utility function, which is defined in (7).
} 


$$
h\left(S_{s}\right)=2 \frac{\exp \left[y_{s}-t\left(x_{f}-x\right)-1-u\right]}{\left(1+\theta_{s}\right) r} \text { for } x \in\left[\widetilde{x}, x_{f}\right]
$$

We can now define the population density as

$$
\begin{gathered}
D_{c} \equiv \frac{h\left(S_{c}\right)}{q\left(x, u_{c}\right)}=2 \frac{\exp \left[2\left(y_{c}-t x-1-u\right)\right]}{\left(1+\theta_{c}\right) r} \text { for } x \in[0, \widetilde{x}] \\
D_{s} \equiv \frac{h\left(S_{s}\right)}{q\left(x, u_{s}\right)}=2 \frac{\exp \left[2\left(y_{s}-t\left(x_{f}-x\right)-1-u\right)\right]}{\left(1+\theta_{s}\right) r} \text { for } x \in\left[\widetilde{x}, x_{f}\right]
\end{gathered}
$$

which is the ratio between square feet of floor space per acre of land and square feet of floor space per dwelling (person). This is a different concept than the structural density or improvements defined by $S_{a}$. As noted above, the improvements (i.e. the intensity of land development) are a measure of building height so a higher $S_{a}$ means that developers construct higher buildings, containing more housing floor space per acre of land. On the other hand, a higher population density means that either the housing floor space is higher or the dwelling size is lower.

Since $H($.$) has constant returns to scale, in equilibrium, the housing industry in each$ area $a$ is such that all firms make zero profit at each $x$, that is

$$
\begin{gathered}
R\left(x, u, \theta_{c}\right)=\frac{\exp \left[2\left(y_{c}-t x-1-u\right)\right]}{\left(1+\theta_{c}\right)^{2} r} \\
R\left(x, u, \theta_{s}\right)=\frac{\exp \left[2\left(y_{s}-t\left(x_{f}-x\right)-1-u\right)\right]}{\left(1+\theta_{s}\right)^{2} r}
\end{gathered}
$$

which implies that

$$
\begin{aligned}
& \frac{\partial R\left(x, u, \theta_{c}\right)}{\partial x}<0, \frac{\partial^{2} R\left(x, u, \theta_{c}\right)}{\partial x^{2}} \geq 0 \\
& \frac{\partial R\left(x, u, \theta_{s}\right)}{\partial x}>0, \frac{\partial^{2} R\left(x, u, \theta_{c}\right)}{\partial x^{2}} \geq 0
\end{aligned}
$$

This equation gives the bid-rent function for land and is found by solving for $R$ in the zero-profit condition, using (14) and (16) for area $c$ and (15) and (17) for area $s$.

We can now formally define the equilibrium.

Definition 1 An urban land-use equilibrium in a duocentric, linear and closed city with absentee landlords is a vector $\left(u, \widetilde{x}, x_{f}, N_{c}, N_{s}\right)$ such that:

$$
\begin{gathered}
R\left(\widetilde{x}, u, \theta_{c}\right)=R\left(\widetilde{x}, u, \theta_{s}\right) \\
R\left(\widetilde{x}, u, \theta_{s}\right)=R_{A}
\end{gathered}
$$




$$
\begin{gathered}
\int_{0}^{\widetilde{x}} \frac{h\left(S_{c}\right)}{q(x, u)} d x=N_{c} \\
\int_{\widetilde{x}}^{x_{f}} \frac{h\left(S_{s}\right)}{q(x, u)} d x=N_{s} \\
N_{c}+N_{s}=N
\end{gathered}
$$

Equation (22) says that the bid rent of CBD- and SBD-workers must intersect at some distance $\widetilde{x}$ while the equation (23) states that the agricultural land rent $R_{A}$ is equal to the land rent at $\widetilde{x}$. Equations (24) and (25) give the two population constraints. Finally, the last equation is the labor market equilibrium condition. Observe that we focus on a closed city, which implies that the total population $N$ is fixed but not $N_{c}$ and $N_{s}$, which are endogenous variables. Observe also that workers living in $\widetilde{x}$ are indifferent between working in the CBD or the SBD. Below $\widetilde{x}$, all residents work in the CBD and $R\left(x, u, \theta_{c}\right)>R\left(x, u, \theta_{s}\right)$ holds for all $x \in[0, \widetilde{x}]$, while beyond $\widetilde{x}$, all residents work in the $\operatorname{SBD}$ and $R\left(x, u, \theta_{c}\right)<R\left(x, u, \theta_{s}\right)$ holds for all $x \in\left[\widetilde{x}, x_{f}\right]$. We have the following result.

Proposition 1 Consider a duocentric, closed and linear city where landlords are absentee. If the utility function is quasi-linear and defined as in (7), the production function $h(S)$ is Cobb-Douglas as in (1), then we obtain the following equilibrium values:

$$
\begin{gathered}
x_{f}^{*}=\frac{y_{c}+y_{s}}{t}-\frac{1}{t} \log \left[\frac{\left(1+\theta_{s}\right) \exp \left(2 y_{c}\right)+\left(1+\theta_{c}\right) \exp \left(2 y_{s}\right)}{1+\theta_{s}+1+\theta_{c}+t N / R_{A}}\right] \\
\widetilde{x}^{*}=\frac{y_{c}}{t}+\frac{1}{2 t}\left[\log \left\{\frac{\left(1+\theta_{s}\right)}{\left(1+\theta_{c}\right)} \frac{1+\theta_{s}+1+\theta_{c}+t N / R_{A}}{\left(1+\theta_{s}\right) \exp \left(2 y_{c}\right)+\left(1+\theta_{c}\right) \exp \left(2 y_{s}\right)}\right\}\right] \\
u^{*}=\frac{1}{2} \log \left[\frac{\left(1+\theta_{s}\right) \exp \left(2 y_{c}\right)+\left(1+\theta_{c}\right) \exp \left(2 y_{s}\right)}{\left(1+\theta_{s}+1+\theta_{c}+t N / R_{A}\right)\left(1+\theta_{s}\right)\left(1+\theta_{c}\right) r R_{A}}\right]-1 \\
N_{c}^{*}=N-\frac{\left(1+\theta_{s}+1+\theta_{c}+t N / R_{A}\right)\left(1+\theta_{s}\right)\left(1+\theta_{c}\right) r R_{A}}{\left(1+\theta_{s}\right)^{2} r t \exp \left[2\left(y_{s}+y_{c}\right)\right]+\left(1+\theta_{c}\right) \exp \left(2 y_{s}\right)}+\frac{\left(1+\theta_{s}\right) R_{A}}{t} \\
N_{s}^{*}=\frac{\left(1+\theta_{s}+1+\theta_{c}+t N / R_{A}\right)\left(1+\theta_{s}\right)\left(1+\theta_{c}\right) r R_{A}}{\left(1+\theta_{s}\right)^{2} r t \exp \left[2\left(y_{s}+y_{c}\right)\right]+\left(1+\theta_{c}\right) \exp \left(2 y_{s}\right)}-\frac{\left(1+\theta_{s}\right) R_{A}}{t}
\end{gathered}
$$

Proof. See Appendix 1.

Denote by

$$
\phi_{\theta} \equiv \frac{1+\theta_{s}}{1+\theta_{c}}
$$

the ratio between the property tax in the suburbs and in the center. 
Proposition 2 We have:

$$
\begin{gathered}
\frac{\partial x_{f}^{*}}{\partial \phi_{\theta}} \gtreqless 0 \Leftrightarrow y_{s}-y_{c} \gtreqless \frac{1}{2} \log (1+t N) \\
\frac{\partial x_{f}^{*}}{\partial N}>0 \\
\frac{\partial x_{f}^{*}}{\partial y_{c}} \gtreqless 0 \Leftrightarrow y_{s}-y_{c} \gtreqless \frac{1}{2} \log \phi_{\theta} \\
\frac{\partial x_{f}^{*}}{\partial y_{s}} \gtreqless 0 \Leftrightarrow y_{s}-y_{c} \lesseqgtr \frac{1}{2} \log \phi_{\theta} \\
\frac{\partial x_{f}^{*}}{\partial t} \gtreqless 0 \Leftrightarrow y_{s}+y_{c} \lesseqgtr \frac{t N}{\phi_{\theta}+1+t N}+\log \left[\frac{\phi_{\theta} \exp \left(2 y_{c}\right)+\exp \left(2 y_{s}\right)}{\phi_{\theta}+1+t N}\right]
\end{gathered}
$$

Proof. See Appendix 1.

Since the empirical analysis is about the relationship between $\phi_{\theta}$ and $x_{f}^{*}$, let us comment only this relationship. An increase in the property tax ratio between the suburbs and the city-center, $\phi_{\theta} \equiv\left(1+\theta_{s}\right) /\left(1+\theta_{c}\right)$, does not always decrease the urban sprawl $x_{f}^{*}$. Observe however that if $y_{s}<y_{c}$, then $\partial x_{f}^{*} / \partial \phi_{\theta}<0$, but if $y_{s}>y_{c}$, then the sign is indeterminate and depends on the above condition. In order to understand this effect, one has to analyze the effect of a property tax on urban sprawl in a monocentric city (Brueckner and Kim, 2003; Song and Zenou, 2006). Using a similar utility function (a log-linear one), Song and Zenou (2006) showed that this effect was always negative. By remembering our discussion about structural versus population density, the intuition of this result is easy to understand. There are two countervailing effects of an increase of the property $\operatorname{tax} \theta$ (here $\theta$ is the property tax everywhere in the city since there is only one business center) on urban sprawl $x_{f}^{*}$. On the one hand, an increase in $\theta$ has a direct negative effect on the profit of developers, which accordingly reduces the level of improvements (or structural density). As a result, for a given size of dwellings, buildings are shorter and thus the population density is lower. Because population is fixed (closed city), it has to be that the city increases in size (this is referred to as the building height effect). On the other hand, an increase in $\theta$ has an indirect negative effect on households' housing consumption because the tax on land and improvements is partly shifted forward to consumers, which yields a higher price of housing and thus a lower dwelling size. Smaller dwellings imply an increase in population density and thus less urban sprawl (this is referred to as the dwelling size effect). The net effect is not ambiguous in Song and Zenou (2006) because consumptions of $z$ (composite good) and $q$ (housing) are highly substitutable since the elasticity of substitution of a log-linear utility function is greater than 
one. Thus, the dwelling-size effect becomes more important and the net effect is such that an increase in $\theta$ decreases urban sprawl.

In the present model with two centers, we still have the same effects but there is a new one. There is now competition in the housing market between CBD- and SBD-workers, which is determined by equation (37) in Appendix 1. Let us explain the way this new effect operates. Using (37), one can see that holding the size of the city-center $\widetilde{x}$ constant, an increase in $\phi_{\theta}$ reduces the city size $x_{f}$. Indeed, when $\theta_{s}$ increases, suburban workers reduce their bid rent (see (21)) while CBD-workers are not directly affected and thus do not directly modify their bid rent (see (20)). However, because the competition for housing between CBD- and SBD-workers is now less fierce, CBD-workers decrease their bid rent. Since $\widetilde{x}$ is held constant and the two bid rents has to intersect at $\widetilde{x}$, the size of the city $x_{f}$ has to decrease. This effect is depicted in Figure 2.

\section{[Insert Figure 2 here]}

The same intuition applies for a decrease $\theta_{c}$, which decreases first the bid rent of CBDworkers and then of SBD-workers. We can solve the general problem where both $\widetilde{x}$ and $x_{f}$ are endogenous by using the population constraints in the city-center (equation (24)) and in the suburbs (equation (25)). In that case, it is not always true that when the ratio $\phi_{\theta}$ increases, the city-center $\widetilde{x}$ and the city $x_{f}$ decrease because of general equilibrium effects. Now if we add the effects described above (i.e. the building height effect and the dwelling size effect) to this one (i.e. the housing competition effect), then the net effect is ambiguous. Proposition 2 gives a condition under which this effect is not ambiguous.

Observe that the interaction between the CBD and the SBD is crucial to understand Proposition 2. Indeed, consider two spatially isolated business districts (the CBD and the SBD) which workers can move between costlessly (with a perfectly elastic demand for labor at wage $y_{s}$ and $y_{c}$ ) and where utility achieved in both locations is fixed at $u^{*}$. Figure A.1 describes this situation. In Appendix 2, we derive the equilibrium results for this case and, not surprisingly, find (see Proposition 4) that the effect of $\phi_{\theta}$ on urban sprawl is not ambiguous and, in particular, an increase in the property tax in each city decreases urban sprawl (i.e. the city size). This result just confirms what was obtained in the case of a monocentric city (Song and Zenou, 2006). On the contrary, in our model, where the interaction between the two business centers is at the heart of the analysis, the result of Proposition 4 does not hold anymore because an increase in the property tax rate of one business center not only has an effect on developers' profit but also on the competition between the two centers in the land market. What is missing in the model of Appendix 2 is 
the key ingredient of nonmonocentric cities: the interaction between the different business centers. This is captured by $\widetilde{x}$ (see equations (22) and (37)), which endogenously determined the size of both the central area and the suburbs. Because the CBD and the SBD interact, the competition in the housing market becomes fiercer, which has an impact on housing prices and on the labor force attached to each center. In our model, each worker freely determines where to work (the $\mathrm{CBD}$ or the SBD) and where to live. In equilibrium, all workers who reside between $x$ and $\widetilde{x}$ finds it optimal to work in the CBD while those who live between $\widetilde{x}$ and $x_{f}$ prefer to work in the SBD.

\section{Developing a national sample of effective tax rates}

Before we test the main result of our theoretical model, i.e. the impact of $\phi_{\theta}$, the ratio between the property tax in the suburbs and in the center, on the spatial pattern of urbanized areas, we first present the steps involved in developing our sample of effective tax rates for a set of urbanized areas in the U.S.

\subsection{Data sources}

For each urbanized area in the U.S., we further divide the area between the central city and the suburbs. Generally, in an urbanized area, there are various taxing entities such as county, township, city, town, school, and special taxing districts. We thus need to construct the aggregated effective tax rates for the "central city" and the "suburbs". We use "central place" 5 as a proxy for "central city". The rest of area in an urbanized area is then defined as "suburbs" in the study.

To construct the aggregated effective tax rates for the central city and the suburbs, we first collect effective tax rates imposed at different levels of taxing jurisdictions in an urbanized area - counties, cities, townships, and school districts. We do not collect effective tax rates from special districts such as fire, water, sewer, etc. as those tax rates are generally not reported by the state agencies. Since special districts are formed to provide services to the inhabitants of a limited area, we argue that the omission of the tax rates from special districts would not have a significant impact on the results of this study.

\footnotetext{
${ }^{5}$ According to US Census Bureau, central place is defined as the core incorporated place(s) or a census designated place of an urban area, usually consisting of the most populous place(s) in the urban area plus additional places that qualify under Census Bureau criteria. If the central place is also defined as an extended place, only the portion of the central place contained within the urban area is recognized as the central place.
} 
Data on the effective tax rates from counties, cities, townships and schools can be collected either from states or local government units. Many state level units, such as the Department of Taxation and Association of County Commissioners, conduct tax rate surveys to collect effective tax rates from various localities and have made effective tax rates available on their websites. $^{6}$ As one of the main purposes of collecting tax rates by the state is to offer a common standard for the comparison of tax rates among taxing jurisdictions, these rates are thus comparable across areas and states. Generally, the effective tax rates are obtained by adjusting the nominal tax rate with the sales/assessment ratio, which is estimated and determined by the state agencies. For those states without available information online, we directly contact the local government units to obtain data on the effective rates imposed by the local jurisdictions such as the counties, cities and school districts.

Finally, in order to construct the aggregated effective tax rate for both the central city and the suburbs in an urbanized area, we also collect spatial datasets which contain the boundaries of central places and urbanized areas and of various taxing jurisdictions such as counties, cities, townships, and school districts. ${ }^{7}$

\subsection{Geographic Information System (GIS) methods}

To distill a single value for the central city and for the suburbs from the tax rates imposed by various taxing entities, we create a weighted average of tax rates by coalescing input tax rates from various jurisdictions based on the localities' spatial relationships within the central city and the suburbs. Next, we describe the steps involved in constructing the aggregated tax rate for the central city and the suburbs in each urbanized area. As an example of our approach, Figure 3 presents three levels of tax rates levied in the central city of Salem, OR Urbanized Area: county, city, and school district.

$$
\text { [Insert Figure } 3 \text { here] }
$$

First, we use GIS techniques to intersect the boundaries of different taxing jurisdictions with the boundary of the central city of Salem, OR Urbanized Area and obtain the proportion of the central city within any given county, city, or school district. Second, we calculate the property tax rates by each of the three taxing jurisdictions: county, city, and school district.

\footnotetext{
${ }^{6}$ Examples of these websites include:

North Carolina: http://www.ncacc.org/taxrate.htm

Illinois: http://www.revenue.state.il.us/Publications/LocalGovernment/00PTAX50.pdf

New York: http://urban.nyu.edu/research/etr/etr-nyc-1999.pdf

${ }^{7}$ These data are available from U.S. Census, or can be purchased from GeoCommunity (a GIS data depot).
} 
Specifically, we show that the central city of Salem, OR Urbanized Area falls into two counties: Marion and Polk - with 90\% of the central city in Marion County and the rest in Polk County. These two counties impose different tax rates and tax assessment ratios. To obtain the effective tax rate for the central city at the county level, we sum the effective tax rates (which are the product of tax rates and ratios) from the two counties adjusted by their area proportions. ${ }^{8}$

We also show that the central city of Salem, OR Urbanized Area contains three cities, Salem, Keizer, and Turner, and that $85 \%$ of the central city is in Salem, $9 \%$ is in Keizer and the rest is located in Turner. To calculate the effective tax rate at the city level, we also need to find out which county the city is located in since we also need to apply the county tax assessment ratio in the calculation. For example, the city of Salem is in both Marion and Polk counties while the cities of Keizer and Turner are only in Marion County. Thus for the city of Salem, GIS techniques are employed to obtain the proportion of the central city that is in the city of Salem, but in different counties. We show that for the $85 \%$ of the central city that is in Salem, $78 \%$ is in Marion County and 7\% is in Polk County. To obtain the effective tax rate for the central city at the city level, we sum the effective tax rates (which are the product of city tax rates and county tax assessment ratios) from the three cities, adjusted by their area proportions. The strategy of computing the effective tax rate at the city level applies to the calculation of the effective tax rate at the school district level. The calculations indicate that the effective tax millage rates levied by the county, city, and school district are 4.26, 5.20, and 5.31, respectively. ${ }^{9}$ Finally, we sum up these three effective tax rates at different levels to obtain the aggregated effective tax millage rate for the central city of Salem, OR Urbanized Area, which is 14.87.

We repeat the steps for the construction of effective property tax rate for the suburbs in Salem urbanized area. Using this approach, we constructed the effective tax rates for the central cities and the suburbs in 445 urbanized areas in the U.S. ${ }^{10}$

\footnotetext{
${ }^{8}$ The aggregate tax rate at the county level is obtained by: Marion County Tax rate $\times$ Marion County Tax assessment ratio $\times$ Proportion of central city in Marion County + Polk County Tax rate $\times$ Polk County Tax assessment ratio $\times$ Proportion of central city in Polk County $=5.487 \times 0.805 \times 90 \%+3.663 \times 0.796 \times 10 \%=4.26$.

${ }^{9} \mathrm{~A}$ millage is a unit equal to one thousandth. Thus, a tax millage rate of 14.57 equals to $1.457 \%$.

${ }^{10}$ We excluded those urbanized areas with a population size larger than five million as they contain too many localities which complicate the calculations.
} 


\section{Unit of analysis, variables, econometric issues and data}

\subsection{Unit of analysis}

In our empirical analysis, the unit of analysis is the urbanized area, which is defined by the Census Bureau as one or more places ('central place') and the adjacent densely settled surrounding territory ('urban fringe') that together have a minimum of 50,000 persons. The urban fringe, generally consisted of contiguous territory incorporated or unincorporated, has a density of at least 1,000 persons per square mile. We use urbanized area as our unit of analysis in exploring the link between differentiated property tax rates and urban development pattern for the following reason. As argued by Brueckner and Fansler (1983: page 480), "by closely approximating the actual built-up portion of the city, the urbanized area is the Census statistical unit which best corresponds to the requirements of the monocentric theory." Since our empirical analysis is also placed within a monocentric urban theory framework, urbanized area is an appropriate proxy for measuring urban scale.

However, it is necessary to note that the urbanized area size is not a good measure of spatial distribution of population. If there are two different cities with identical populations but with different urbanized area sizes, it is possible that the population associated with the city containing the smaller urbanized area actually has a broader spatial distribution because a greater portion of population living at a lower density outside the urbanized area. Of course, the opposite could also be true and smaller urbanized areas could be associated with greater density within the urbanized area. ${ }^{11}$ To address this issue, we also include two measures of decentralization, as described in more detail in the next section, to consider relative densities of population and employment at two locations in an urban area. In addition, future study will be carried out to test the connection between urban development pattern and differentiated property tax rates using the Metropolitan Statistical Area (MSA) as the unit of analysis.

\subsection{Dependent variables}

There is a copious set of measures of urban development pattern developed by various disciplines. ${ }^{12}$ Following the literature, we adopt three measures of urban development pattern:

\footnotetext{
${ }^{11}$ We thank an anonymous referee for this comment.

${ }^{12}$ For a review on urban form measures, see Clifton et al. (2008).
} 
urban scale (Brueckner and Fansler, 1983), and decentralization of population (Edmonston and Guterbock, 1984) and employment (Glaeser and Kahn, 2001). ${ }^{13}$

Urban scale is measured by the urbanize area sizes in this study. To measure decentralization, we use population and employment density gradients respectively. Clark (1951) is generally credited as the first to estimate urban population density gradients. McDonald (1989) provides a comprehensive review. We adopt a two-point estimation procedure of density gradient developed and proved with reliability by a widespread of studies (Edmonston, 1983; Edmonston and Guterbock, 1984). The estimates of density gradients can be made using available data on two areas: the central city and the total urbanized area. More specifically, the mathematical notation of the assumption that population density in an urban area declines as a negative exponential function of distance from city center is:

$$
D(x)=b e^{-a x}
$$

where $D(x)$ represents the population density at distance $x$ from the city center, $b$ is the intercept (or the central density) and $a$ is the density gradient of the function.

A lower value in the density gradient indicates that an urban population or employment is more dispersed or spread out over the urban land area. For example, a value of 1.5 for the density gradient indicates a highly concentrated urban population or employment while a value of 0.01 for the density gradient indicates a dispersed urban population or employment with equal density over the urban area.

Mills (1972) proposed a clever method for estimating population density gradients using extremely limited data sources. ${ }^{14}$ For a circular city, population density $D(x)$ at location $x$ can be written as:

$$
D(x)=\frac{N(x)}{2 \pi x}
$$

where $N(x)$ is the number of people living in an infinitesimal ring $x$ miles from the city center and $2 \pi x$ is the land area for a circular city in an infinitesimal ring $x$ miles from the city center. As a result, by using the value of $D(x)$ in (32) and by integrating by parts, the

\footnotetext{
${ }^{13}$ As pointed out by Glaeser and Kahn (2001), measures of employment centralization include the share of employment within a three, or ten mile distance from the city center, the distance between the median employee and the city center, and the employment density gradient. We use the density gradient in this study, as described below.

${ }^{14}$ See McMillen (2006) for an exposition of this method.
} 
total number of residents in a circular urbanized area of size (or radius) $z$ is given by:

$$
\begin{aligned}
N(z) & =\int_{0}^{z} 2 \pi x b e^{-a x} d x \\
& =\frac{2 \pi b}{a^{2}}\left[1-(1+a z) e^{-a z}\right]
\end{aligned}
$$

Denote by $r_{1}$ the central-city radius. Then, the total number of residents of the central city is equal to:

$$
N\left(r_{1}\right)=\frac{2 \pi b}{a^{2}}\left[1-\left(1+a r_{1}\right) e^{-a r_{1}}\right]
$$

while the total number of residents in an urbanized area of size/radius $r_{2}$ is:

$$
N\left(r_{2}\right)=\frac{2 \pi b}{a^{2}}\left[1-\left(1+a r_{2}\right) e^{-a r_{2}}\right]
$$

The city is thus defined by two concentric circles (the central city and the urbanized area) with radii $r_{1}$ and $r_{2}$. With equations $N\left(r_{1}\right)$ and $N\left(r_{2}\right)$, we can implicitly solve for $a$ and $b$ and obtain:

$$
\begin{aligned}
& b=\frac{a^{2} N\left(r_{2}\right)}{2 \pi\left[1-\left(1+a r_{2}\right) e^{-a r_{2}}\right]} \\
& \frac{N\left(r_{1}\right)}{N\left(r_{2}\right)}=\frac{1-\left(1+a r_{1}\right) e^{-a r_{1}}}{1-\left(1+a r_{2}\right) e^{-a r_{2}}}
\end{aligned}
$$

The Van Wijngaarden-Dekker-Brent Method (Brent, 1973) ${ }^{15}$ is used to solve for $a$ in the nonlinear equation of (34). To implement the above two-point estimation procedure, we need to have data on two population and employment sizes and two land areas.

After computing the three dependent variables, we find that the correlation between urban scale and population (or employment) density gradient is -0.33 (or -0.31 ) and the correlation between two density gradients is 0.97 . This implies that larger cities are associated with higher degree of decentralization. In the next section, we list independent variables which are employed in determining the urban scale and the level of decentralization.

\subsection{Independent variables}

An empirical test based on the above theoretical analysis is extremely useful to facilitate the debate on the relationship between differentiated property tax and urban development pattern. In particular, our main variable of interest is the ratio of property tax rate in suburbs to the rate in central city, as described in Section 3.

\footnotetext{
${ }^{15}$ The numerical method programmed can be found from the following web link: http://mymathlib.webtrellis.net/roots/amsterdam.html.
} 
To control for other determinants of urban development pattern, we return to urban economic theory and the literature for guidance to formulate hypotheses about urban sprawl and decentralization.

\section{(i) The monocentric city model}

Alonso (1964), Mills (1967), Muth (1969), and Wheaton (1974) all provide a justification for including the explanatory variables including population, income, transportation (or commuting) costs, and agricultural land rent to determine the urban spatial extent. The intuition of including these variables is also stated in Brueckner and Fansler (1983)'s study. A recent study by McGrath (2005) confirms the validity of this set of variables. An increase in the urban population would increase the urban spatial extent since more people would require more housing. An increase in agricultural land rent would lead to a higher opportunity cost of urban land and thus, make the city more compact. A higher level of income would imply an increase in housing demand and thereby, leads to a larger city. Finally, an increase in transportation or commuting cost would lower disposal income at all locations and thus, reduce city size. Given the confluence of an expanding population, rising incomes, and falling commuting costs, it is not surprising that most U.S. cities have expanded rapidly in recent decades.

In identifying the determinants of urban decentralization, Brueckner (2000) argues that the same set of variables - increasing population and income, undervalued transportation costs and agricultural land value - can be used to provide a diagnosis of causes of urban sprawl. Baum-Snow (2007) includes variables such as population, characteristics of the income distribution, and number of highways to explore the determinants of suburbanization. In exploring causes of employment decentralization, Glaeser and Kahn (2001) suggest that population, land cost, and transportation cost are associated with employment decentralization. Thus, following the urban economic theory and the literature, we also include these variables to explore the determinants of population and employment decentralization.

\section{(ii) Polycentric urban form}

The extent to which cities are monocentric has declined over time and cities have become increasingly polycentric (Fujita and Ogawa, 1980; Ogawa and Fujita, 1982). It has been shown that cities specializing in sectors with stronger agglomeration economies tend to be monocentric while those with weaker agglomeration economies are more likely to sprawl and decentralize (Burchfield et al., 2005; Glaeser and Kahn, 2001). 


\section{(iii) City amenity features}

There are evidences that features such as city topography, terrain, and climate would affect the way the city is developed (Burchfield et al., 2005). In this study, we include a variable on climate to test if cities with a pleasant climate are more likely to develop extensively or decentralize. One disamenity in the central city is its potential higher crime rate than in the suburbs. This disamenity is likely to induce people to move away from the central city (Mattison, 1950). Thus, we include a variable on crime rate in the central city to test if it has an effect on population and employment decentralization.

\subsection{Data and specification}

To summarize the preceding section, the predictions suggest that cities will expand or decentralize both in population or employment if: the population size is greater, the income is higher, the transportation or commuting cost is lower, the agricultural land value is lower, the cities have an employment structure which is less of agglomeration economies, the climate is temperate, the crime rate in central city is high, and the property tax rate in the central city is higher than the rate in the suburbs.

We describe the data used to construct the list of variables here. In the regression model, the dependent variables are urban scale measured by the size, in acres, of the urbanized area in the year 2000, and urban decentralization, measured by population and employment density gradients in the year 2000 respectively. For the independent variables, the population variable represents the 2000 urbanized area population. The income variable is a measure of the 2000 median household income. The commuting cost is captured by three proxies: highway lane miles per capita in the urbanized area, the number of commuters using public transit in 2000 (Brueckner and Fansler, 1983), and the number of commuters using automobiles in 2000. It is assumed that a higher value of highway lane miles, a smaller number of people using transit, or a greater number of people using cars are associated with ease of transportation system usage and thus a lower level of commuting costs. The variable of agricultural land value is obtained by constructing a weighted average of median agricultural land value per acre for each urbanized area based on the area proportions of counties in relation to the urbanized area using GIS techniques, as data on agricultural land rent is only available at county level. The variable climate is measured by the annual mean daily average temperature in the urbanized area in 2000. The variable crime is measured by the crime rate in the central city. The employment structure variable is measured by the share of labor force in services in 2000. Finally, as mentioned above, the ratio of 1997 property 
tax rate in suburbs to the rate in central city is constructed according to the steps described in section 3. Note that we lag the ratio by three years because the effect of differentiated property tax rates on the size of an urbanized area is not instantaneous, but rather takes time.

Data sources and measurements of both dependent and independent variables are summarized in Table 1. Table 2 shows descriptive statistics for all the variables described. The statistics show that average urban scale is 90,424 acres, which is 12 times the smallest urban scale. The statistics also show that the density gradients and the independent variables vary across the cities. It is clear that there are significant disparities across the urbanized areas in population, income, agricultural land rent, urban transport infrastructure, and property tax rates, among other things. We want to know to what extent these differences explain the spatial scales and level of centralization of these urbanized areas. More importantly, we want to explore if differentiated property tax rates within an urbanized area have any impact on urban development patterns. We present the findings in the next section.

\section{[Insert Tables 1 and 2 here]}

Before we test these predictions by regressing urban scale and decentralization on the above listed variables, it is necessary to note several econometric issues. First, it is possible that the income distribution is endogenous to urban expansion and decentralization. In order to account for the potential endogeneity of income, following the procedures described by Baum-Snow (2007), we create simulated income based on a combination of employment shares for each urbanized area and skill prices, which are built using wages and salary income of individuals working at least 48 weeks.

Second, to account for the potential endogeneity of highway lane miles, the highway lane miles in a 1947 national interstate highway plan by 1950 urbanized area boundary is used as an instrument. To test the validity of the instrument, the $F$-test for the significance of the instrument is 12.54 and statistically significant. Furthermore, an examination of the 1st stage results (not shown for brevity) suggests that the coefficient associated with the highway lane miles in the 1947 plan is statistically significant. For diagnostics of the potential endogeneity, we perform a Hausman endogeneity test. We find that the Hausman statistic is significant at the 0.001 level. The small $p$-value indicates that there is a significant difference between the $I V$ and $O L S$ coefficients, and that the $O L S$ model assuming the exogeneity of the highway lane miles is not consistent.

Third, examining the link between employment structure and urban scale by using a measure of the extent to which employment is centralized in potentially problematic: more 
compact cities will typically have more centralized employment (Burchfield et al., 2005). Thus we measure the extent to which the city is specialized in business services, following the suggestions by Burchfield et al. (2005) and Glaeser and Kahn (2001).

Fourth, there is one potential problem in assuming the exogeneity of the property tax. For example, a positive unobservable decentralization shock to the central city could in fact be the causes of population and employment decentralization and may, in turn, instigates the need for higher property tax rate to support infrastructure such as sewer-lines, waterlines, gas lines, phone lines, streets, and gutters with declining tax base as population and businesses are moving away. If this "reverse" channel of causation is active, the OLS estimates of the coefficient of tax rate ratio are upward biased. In Song and Zenou (2006)'s study of urban scale and property tax, the average level of property tax rate in the urbanized area is found to be endogenous to urban expansion. The variable of magnitude of state aid to schools is used to instrument the average level of property tax rate in the urbanized area. In this present study, we are not able to find a valid instrument to test for the potential endogeneity of property tax rate ratio. ${ }^{16}$ We will therefore be very careful when interpreting the results in terms of causality.

Incorporating the above listed factors, a direct test of Propositions 1 and 2 is to test equation (27), which econometric counterpart can be written as:

$$
x_{f, i}=\alpha_{0}+\alpha_{1} \phi_{\theta, i}+\alpha_{2} N_{i}+\alpha_{3} y_{i}+\alpha_{4} R_{A, i}+\alpha_{5} t_{i}+\alpha_{6} T_{i}+\alpha_{7} E M P_{i}+\varepsilon_{i}
$$

where $i$ is an index for the urban area, $x_{f, i}$ is the urban scale, $\phi_{\theta, i}$ is the property tax rate ratio, $N_{i}$ is the total population, $y_{i}$ is the adjusted income, $R_{A, i}$ is the agricultural land rent, $t_{i}$ is the commuting cost, $T_{i}$ is the average temperature, $E M P_{i}$ is the employment share in services, and $\varepsilon_{i}$ is a white noise error term. ${ }^{17}$

We have noted that the urbanized area size is not a good measure of spatial distribution

\footnotetext{
${ }^{16}$ To be valid, the instrument must be correlated with property tax rate ratio but also exogenous to city size. We gather data on the ratio of state aid to schools between the central city and the suburb as a possible instrument variable to instrument the ratio of property tax rates. As data on state aid to schools is available at county level, we construct a weighted average of state aid to schools for the central cities and suburbs in each urbanized area based on the area proportions of central cities and suburbs in relation to the counties using GIS techniques. We then compute the ratio of state aid to schools between the central city and the suburb for each urbanized area as a potential instrument. However, the F-test for the significance of the instrument is not statistically significant.

${ }^{17}$ Contrary to the model, we do not split the income and the population into two areas of the urban area (i.e., the central city and the suburbs). Rather, we use data on the total income and the total population in the urban area. We have also tested the model with variables on income and population disaggregated by the central city and the suburbs. However, the disaggregated variables are not significant.
} 
of population or employment. We therefore include two more dependent variables to consider relative densities of population and employment at two locations in an urban area. We have the following econometric equation:

$$
G_{i}=\alpha_{0}+\alpha_{1} \phi_{\theta, i}+\alpha_{2} N_{i}+\alpha_{3} y_{i}+\alpha_{4} R_{A, i}+\alpha_{5} t_{i}+\alpha_{6} T_{i}+\alpha_{7} C R_{i}+\alpha_{8} E M P_{i}+\varepsilon_{i}
$$

where $G_{i}$ are the density gradients for population or employment, $C R_{i}$ is the crime rate in the central city, and the other variables are defined as in equation (35).

Given that the theory provides no guidance as to the functional form of the estimating equation, the empirical work makes use of the Box - Cox transformation. The optimal value of the functional form parameter $\lambda$ equals 0.46 , indicating that a square-root transformation of the variables is appropriate. This is consistent with Brueckner and Fansler (1983)'s specified functional form of the estimating equation.

\section{Empirical results}

Table 3 presents regression estimates from various specifications of (35) and (36). The first three columns present estimates with four main variables: population, income, agricultural land rent, and commuting cost, in addition to the variable on property tax rate ratio. The first column presents the instrumental variable estimates with highway lane miles as the endogenous variable and the highway lane miles in a 1947 national interstate highway plan by 1950 urbanized area boundary as an instrument. The second and third columns present the ordinary least squares $(O L S)$ estimates, with variables of people using transit or using automobiles as variables on commuting cost respectively. The fourth column presents the instrumental variable estimates with an extended set of variables including property tax rate ratio, four main variables under standard monocentric framework, and additional control variables such as climate, and employment share in the urbanized area. The variable of highway lane miles is the endogenous variable.

\section{[Insert Table 3 here]}

Results from these four sets of estimates indicate that the signs of most estimated coefficients conform to the expectations from the theory. Concerning the control variables, the population and adjusted income variables have positive and significant coefficients, indicating that the spatial size of urbanized areas is an increasing function of the population and income. The results also show that the estimated coefficient of the variable of highway lane miles (instrumented by the highway lane miles in the 1947 plan) is positive and significant and 
that the coefficient of the variable of the total number of people using transit to commute to work is negative and significant. Both of these two variables are used as proxies for commuting costs respectively. Thus, since more highway lane miles and a smaller number of people using transit are associated with a lower level of commuting costs, the results indicate that there is a negative relationship between the urban size and the commuting costs. The estimated coefficient of agricultural rent variable is significant and negative at $10 \%$ level in two of the specifications, indicating that a lower agricultural land rent in the urbanized area is associated with a more expansive urban area. The estimated coefficient of climate variable is significant and positive, indicating that a temperate climate is associated with more expansive urban development. The estimated coefficient of the employment share in business service variable is significant and negative, suggesting that the share of employment in services is associated with compact urban development.

In particular, the influence of the ratio of property tax rate in suburbs to the rate in central city on the spatial extent of urban areas is of primary interest to this research. Across the specifications, the coefficient of the property tax ratio is negative and statistically significant. The result supports what has been predicted by the theory (Propositions 1 and 2) but giving a precise sign to the relationship between $\phi_{\theta}$ and $x_{f}$ : the lower the property tax rate in suburbs in comparison to the rate in central city, the larger the spatial scale of urbanized areas.

To further explore the determinants of urban decentralization, we regress on the population and employment gradients and the regression estimates are presented in the fifth and sixth columns respectively in Table 3 . Recall that a higher value of the density gradient means that an urban population or employment is more centralized, thus, the negative coefficients of the income, the highway lane miles, and climate variables indicate that higher income, more highways built, and more temperate climate are associated with decentralization of both population and employment, and positive coefficients of agricultural land rent and employment share in service variables suggest that higher agricultural land value and greater share of the employment in services are associated with centralization. The population and the crime rate variables are not statistically significant in both specifications.

The links between property tax ratio and population and employment density gradients are of primary interest to this research. In both regressions, the coefficients of the property tax ratio are positive and statistically significant. The results suggest that the higher the property tax rate in central city in comparison to the rate in suburbs, the more centralized the urban areas are. We know from a previous study (Song and Zenou, 2006) that higher property tax rate is associated with more compact urban development. Taking these together, our 
results suggest that higher property tax rate in central city in comparison to the suburbs is correlated with more compact development in the central city, which in turn results in denser population or employment in the central city and more centralized urban area.

\section{Conclusion}

In recent years, urban sprawl in the U.S. has become one of Americans' top public concerns. Urban sprawl can be attributed to multiple causes. In this paper, we use both theoretical model and empirical analysis to examine whether the differentiated property tax rates within urban areas can be one of causes of urban sprawl.

Specifically, this paper has examined the link between urban development pattern, quantified by urban scale and the level of urban centralization, and the ratio of property tax rate in the suburbs to the rate in central city through both theoretical and empirical analyses. The theoretical model has not clear prediction for the relationship between these two variables. We give, however, a condition that guarantees that this relationship is negative. Contrary to the monocentric-city model with property tax and housing (Song and Zenou, 2006), there is an additional effect due to the duocentric nature of the city. Indeed, the CBD and the SBD not only compete to attract workers but there is also a fierce competition in the housing market between CBD- and SBD-workers. This additional effect complicates the relationship between the ratio of property tax rate in the suburbs to the rate in central city and urban sprawl, which implies that the sign of this relationship cannot be explictly determined.

Therefore, we test this relationship. For that, we first develop a dataset of the effective property tax rates using GIS method for central cities and suburbs in 445 urbanized areas. We then estimate a set of regression equations relating an urbanized area's size and centralization of population and employment to a ratio of property tax rate in the suburbs to the rate in central city, controlling for a set of variables such as population, income, agricultural rent, transportation expenditure, climate, crime, and employment structure. Results from the empirical analysis are consistent with findings from the theoretical reasoning, suggesting that lower tax rate in suburbs induces more developments outward, and thus a more expansive and decentralized urban area.

To provide a sense of the magnitude of the influence from varied tax rates within an urban area, we evaluate the elasticity of urban scale with respect to the property tax ratio. The calculated elasticity evaluated at sample mean is -0.27 , which implies that a $1 \%$ increase in the ratio of property tax rate in suburbs to the rate in central city reduces the urban spatial 
extent by $0.27 \%$. We can evaluate the importance of differentiated tax rates for explaining urban expansion decline by examining the counterfactual evolution of urban scale where tax rate in the central city equals to the rate in the suburbs. An elasticity of -0.27 implies that had the ratio of effective property tax rate in the suburbs to the rate in the central city been one (rather than being 0.91 on average), the urban size would have reduced by 3 percent.

For several reasons, however, the above research results must be interpreted with caution. First, since our unit of analysis is the urbanized area, our results on the estimated coefficients are not comparable to the results from McGrath (2005) and Burchfield et al. (2006). Future study using the MSA as the unit of analysis is needed for the comparison across studies in the literature. Second, it is possible that the tax rate ratio is endogenous. We are not able to identify an instrument and to test the potential endogeneity in the present study. Future efforts are necessary in identifying exogenous factors that could instrument the tax rate ratio. It is necessary to note that although an empirical analysis with panel data is likely to address the issue of endogeneity, it is quite demanding to construct a panel of effective tax rates. Third, our two measures of decentralization are based on two-point estimation of the negative exponential function. In typical empirical analyses of population and employment density gradients, the computation is time-consuming. Population, employment, and land data are collected by census tracts, zip codes, or other small areal unit, distances from these units to a central point are computed and then the natural logarithm of population and employment is regressed on distance to estimate the gradients. Future analyses working with census tract data for estimating the negative exponential function are needed for more refined computations of population and employment density gradients. Lastly, much needs to be learned to gain a better understanding of the mechanisms by which different property taxes have caused the urban development patterns documented in this study.

Acknowledging the limitations, we believe our findings provide some preliminary evidences on the connection between varied tax rates and urban spatial pattern. In addition, the research finding has important policy implications for urban development in the U.S. Given the level of government fragmentation at the local level, varying property tax rates within urban areas is a common practice in the U.S. It is thus essential to note the associated effects of fragmented urban areas on urban development patterns. This study has demonstrated that lower property tax rates in suburbs in comparison to central cities could induce spillover of development outward. For this reason, remedies for urban sprawl adopting property tax strategies could be more effective if executed at the regional scale with cooperation among central city and suburban governments. 


\section{References}

[1] Alonso, W. (1964), Location and Land Use, Cambridge, MA: Harvard University Press.

[2] Arnott, R.J. and J.G. MacKinnon (1977), "The effects of the property tax: A general equilibrium simulation," Journal of Urban Economics 4, 389-407.

[3] Baum-Snow, N. (2007), "Did highways cause suburbanization?" Quarterly Journal of Economics 122, 775-805.

[4] Brent, R.P. (1973), Algorithms for Minimization without Derivatives, Englewood Cliffs, NJ: Prentice-Hall.

[5] Brueckner, J.K. (1987), "The structure of urban equilibria: A unified treatment of the Muth-Mills model," In: E.S. Mills (Ed.), Handbook of Regional and Urban Economics, Vol. 2, Amsterdam: North Holland, pp. 821-845.

[6] Brueckner, J.K. (2000), "Urban sprawl: Diagnosis and remedies," International Regional Science Review 23, 160-171.

[7] Brueckner, J.K. and D.A. Fansler (1983), "The economics if urban sprawl: Theory and evidence on the spatial sizes of cities," Review of Economics and Statistics 65, 479-482.

[8] Brueckner, J.K. and H. Kim (2003), "Urban sprawl and the property tax," International Tax and Public Finance 10, 5-23.

[9] Brueckner, J.K. and Y. Zenou (2003), "Space and unemployment: The labor-market effects of spatial mismatch," Journal of Labor Economics 21, 242-266.

[10] Burchfield, M., Overman, H.G., Puga, D. and M.A. Turner (2006), "Causes of sprawl: A portrait from space," Quarterly Journal of Economics 121, 587-633.

[11] Case, K. E. and J. H. Grant (1991), "Property tax incidence in a multijurisdictional neoclassical model," Public Finance Quarterly 19, 379-392.

[12] Clark, C. (1951), "Urban population densities, Journal of the Royal Statistical Society 114, 490-494.

[13] Clifton, K., Knaap, G.J., Ewing, R., and Y. Song (2008), "Quantitative analysis of urban form: A multidisciplinary review," Journal of Urbanism: International Research on Placemaking and Urban Sustainability 1, 1-31. 
[14] Downs, A. (1998), "The big picture: Why America's cities are growing," Brookings Review 16, 8-11.

[15] Duranton, G. (2006), "Human capital externalities in cities: Identification and policy issues," In: R. Arnott and D. McMillen (Eds.), A Companion to Urban Economics, New York: Blackwell, pp. 24-39.

[16] Edmonston, B. (1983), "Metropolitan population deconcentration in Canada: 19411976," Canadian Studies in Population 10,49-70.

[17] Edmonston, B. and T. Guterbock (1984), "Is surbanization slowing down? Recent trends in population deconcentration in U.S. metropolitan areas," Social Forces 62, 905-925.

[18] Ewing, R. (1997), "Is Los Angeles-style sprawl desirable?," Journal of American Planning Association 63, 107-126.

[19] Fujita, M. (1989), Urban Economic Theory, Cambridge: Cambridge University Press.

[20] Fujita, M. and H. Ogawa (1980), "Equilibrium land use patterns in a nonmonocentric city," Journal of Regional Science 20, 455-475.

[21] Fujita, M. and J-F. Thisse (2002), Economics of Agglomeration, Cambridge: Cambridge University Press.

[22] Fujita, M., Thisse, J-F. and Y. Zenou (1997), "On the endogeneous formation of secondary employment centers in a city," Journal of Urban Economics 41, 337-357.

[23] George, H. (1879), Progress and Poverty: An Inquiry into the Cause of Industrial Depressions and of Increase of Want with Increase of Wealth, New York: Robert Schalkenbach.

[24] Glaeser, E.L. and M.E. Kahn (2001), "Decentralized employment and the transformation of the American city," Brookings-Wharton Papers on Urban Affairs 2, 1-64.

[25] Glaeser, E.L. and M.E. Kahn (2004), "Sprawl and urban growth," In: J.V. Henderson and J.-F. Thisse (Eds.), Handbook of Regional and Urban Economics Vol. 4, Amsterdam: Elsevier Science, pp. 2498-2527.

[26] Glaeser, E.L. and D.C. Maré (2001), "Cities and skills," Journal of Labor Economics $19,316-342$. 
[27] Henderson, V. and A. Mitra (1996), "The new urban landscape developers and edge cities," Regional Science and Urban Economics 26, 613-643.

[28] Mattison, W.J. (1950), "Blight and mass transportation in Metropolitan communities," Virginia Law Review 36, 859-872.

[29] McDonald, J. (1989), "Econometric studies of urban population density: A survey," Journal of Urban Economics 26, 361-385.

[30] McGrath, D.T. (2005), "More evidence on the spatial scale of cities, Journal of Urban Economics 58, 1-10.

[31] McGuire, T.J. and D.L. Sjoquist (2003), "Urban sprawl and the finances of state and local governments," In: D.L. Sjoquist (Ed.), State and Local Finances under Pressure, London: Edward Elgar Publishing.

[32] McMillen, D.P. (2006), "Testing for monocentricity," In: R. Arnott and D. McMillen (Eds.), A Companion to Urban Economics, Boston: Blackwell Publishing, pp. 128-140.

[33] Mills, E.S. (1967), "An aggregative model of resource allocation in a Metropolitan area," American Economic Review 57, 197-210.

[34] Mills, E.S. (1972), Studies in the Structure of the Urban Economy, Baltimore, MD: Resources for the Future, Inc.

[35] Mills, E.S. (1998), "The economic consequences of a land tax," In: D. Netzer (Ed.), Land Value Taxation: Can It and Will It Work Today?, Cambridge (MA): Lincoln Institute of Land Policy, pp. 31-48.

[36] Muth, R.F. (1969), Cities and Housing, Chicago: University of Chicago Press.

[37] Nechyba, T.J. and R.P. Walsh (2004), "Urban sprawl," Journal of Economic Perspectives 18, 177-200.

[38] Oates, W.E. and R.M. Schwab (1997), "The impact of urban land taxation: The Pittsburgh experience," National Tax Journal 50, 1-21.

[39] Ogawa, H. and M. Fujita (1982), "Multiple equilibria and structural transition of nonmonocentric urban configurations," Regional Science and Urban Economics 12, 161-196. 
[40] Rappaport, J. (2005), "The shared fortunes of cities and suburbs," Federal Reserve Bank of Kansas City Economic Review 3, 33-60.

[41] Skaburskis, A. and R. Tomalty (1997), "Land value taxation and development activity: The reaction of Toronto and Ottawa developers, planners, and municipal finance officials," Canadian Journal of Regional Science 20, 401-417.

[42] Smith, T.E. and Y. Zenou (1997), "Dual labor markets, urban unemployment and multicentric cities," Journal of Economic Theory 76, 185-214.

[43] Song, Y. and Y. Zenou (2006), "Property tax and urban sprawl: Theory and implications for U.S. cities," Journal of Urban Economics 60, 519-534.

[44] The Sierra Club (1999), "The dark side of the American dream: the costs and consequences of suburban sprawl," The Sierra Club, San Francisco, CA: http://www.sierraclub.org/sprawl/report98/.

[45] Wheaton, W.C. (1974), "A comparative static analysis of urban spatial structure," Journal of Economic Theory 9, 223-237.

[46] Zenou, Y. (2009), Urban Labor Economics, Cambridge: Cambridge University Press, forthcoming. 


\section{Appendix 1. Proof of propositions of the model in the text}

Proof of Proposition 1. Solving equation (22) using (20) and (21) yields:

$$
\widetilde{x}=\frac{x_{f}}{2}+\frac{1}{2 t}\left[y_{c}-y_{s}+\log \left(\frac{1+\theta_{s}}{1+\theta_{c}}\right)\right]
$$

Solving equation (23) using (21) gives:

$$
u=y_{s}-1+t\left(\widetilde{x}-x_{f}\right)-\log \left(1+\theta_{s}\right)-\frac{1}{2} \log \left(r R_{A}\right)
$$

Furthermore, solving equation (24) using (18) leads to:

$$
N_{c}=\frac{\exp \left[2\left(y_{c}-1-u\right)\right]}{\left(1+\theta_{c}\right) r t}(1-\exp [-2 t \widetilde{x}])
$$

while solving (25) using (19) gives:

$$
N_{c}=N-\frac{\exp \left[2\left(y_{s}-1-u\right)\right]}{\left(1+\theta_{s}\right) r t}\left(1-\exp \left[2 t\left(\widetilde{x}-x_{f}\right)\right]\right)
$$

Now, by combining (38) and (40), we obtain the following relationship between $N_{c}$ and $u$ :

$$
N_{c}=N-\frac{1}{\left(1+\theta_{s}\right) r t \exp \left[2 y_{s}\right] \exp [2(1+u)]}+\frac{\left(1+\theta_{s}\right) R_{A}}{t}
$$

which means that

$$
N_{s}=\frac{1}{\left(1+\theta_{s}\right) r t \exp \left[2 y_{s}\right] \exp [2(1+u)]}-\frac{\left(1+\theta_{s}\right) R_{A}}{t}
$$

By combining (37) and (38), we obtain the following relationship between $\widetilde{x}$ and $u$ :

$$
t \widetilde{x}=y_{c}-\log \left(1+\theta_{c}\right)-\frac{1}{2} \log \left(r R_{A}\right)-(1+u)
$$

By plugging (37) into (42), we obtain the following relationship between $x_{f}$ and $u$ :

$$
t x_{f}=y_{c}+y_{s}-\log \left[\left(1+\theta_{s}\right)\left(1+\theta_{c}\right)\right]-\log \left(r R_{A}\right)-2(1+u)
$$

which can be written as

$$
\exp [2(1+u)]=\frac{\exp \left[y_{c}+y_{s}-t x_{f}\right]}{\left(1+\theta_{s}\right)\left(1+\theta_{c}\right)\left(r R_{A}\right)}
$$


By plugging (37) into (39), we obtain:

$$
N_{c}=\frac{\exp \left[2\left(y_{c}-1-u\right)\right]}{\left(1+\theta_{c}\right) r t}-\frac{\exp \left[y_{s}+y_{c}-2(1+u)-t x_{f}\right]}{\left(1+\theta_{s}\right) r t}
$$

By plugging (37) into (40), we obtain:

$$
N_{c}=N-\frac{\exp \left[2\left(y_{s}-1-u\right)\right]}{\left(1+\theta_{s}\right) r t}+\frac{\exp \left[y_{c}+y_{s}-2(1+u)-t x_{f}\right]}{\left(1+\theta_{c}\right) r t}
$$

Now, by combining (45) and (46), we obtain the following relationship between $u$ and $x_{f}$ :

$$
=\frac{\exp [2(1+u)]}{\left(1+\theta_{s}\right) \exp \left[2 y_{c}\right]+\left(1+\theta_{c}\right) \exp \left[2 y_{s}\right]-\left(2+\theta_{s}+\theta_{c}\right) \exp \left[y_{c}+y_{s}-t x_{f}\right]}
$$

Finally, by combining (44) and (47), we obtain the equilibrium value of the city-fringe:

$$
x_{f}^{*}=\frac{y_{c}+y_{s}}{t}-\frac{1}{t} \log \left[\frac{\left(1+\theta_{s}\right) \exp \left(2 y_{c}\right)+\left(1+\theta_{c}\right) \exp \left(2 y_{s}\right)}{1+\theta_{s}+1+\theta_{c}+t N / R_{A}}\right]
$$

We can now calculate the other equilibrium values. By plugging $x_{f}^{*}$ in (43), we have:

$$
u^{*}=\frac{1}{2} \log \left[\frac{\left(1+\theta_{s}\right) \exp \left(2 y_{c}\right)+\left(1+\theta_{c}\right) \exp \left(2 y_{s}\right)}{\left(1+\theta_{s}+1+\theta_{c}+t N / R_{A}\right)\left(1+\theta_{s}\right)\left(1+\theta_{c}\right) r R_{A}}\right]-1
$$

By plugging $x_{f}^{*}$ in $(37)$, we obtain:

$$
\widetilde{x}^{*}=\frac{y_{c}}{t}+\frac{1}{2 t}\left[\log \left\{\frac{\left(1+\theta_{s}\right)}{\left(1+\theta_{c}\right)} \frac{1+\theta_{s}+1+\theta_{c}+t N / R_{A}}{\left(1+\theta_{s}\right) \exp \left(2 y_{c}\right)+\left(1+\theta_{c}\right) \exp \left(2 y_{s}\right)}\right\}\right]
$$

Finally, plugging $u^{*}$ into (41) gives:

$$
N_{c}^{*}=N-\frac{\left(1+\theta_{s}+1+\theta_{c}+t N / R_{A}\right)\left(1+\theta_{s}\right)\left(1+\theta_{c}\right) r R_{A}}{\left(1+\theta_{s}\right)^{2} r t \exp \left[2\left(y_{s}+y_{c}\right)\right]+\left(1+\theta_{c}\right) \exp \left(2 y_{s}\right)}+\frac{\left(1+\theta_{s}\right) R_{A}}{t}
$$

and since $N_{s}^{*}=N-N_{c}^{*}$, we have:

$$
N_{s}^{*}=\frac{\left(1+\theta_{s}+1+\theta_{c}+t N / R_{A}\right)\left(1+\theta_{s}\right)\left(1+\theta_{c}\right) r R_{A}}{\left(1+\theta_{s}\right)^{2} r t \exp \left[2\left(y_{s}+y_{c}\right)\right]+\left(1+\theta_{c}\right) \exp \left(2 y_{s}\right)}-\frac{\left(1+\theta_{s}\right) R_{A}}{t}
$$


Proof of Proposition 2. First, in order to express $x_{f}^{*}$ in terms of the ratio $\phi_{\theta} \equiv$ $\left(1+\theta_{s}\right) /\left(1+\theta_{c}\right)$, we normalize the agricultural land rent as follows: $R_{A} \equiv 1 /\left(1+\theta_{c}\right)$. It is easy to verify that this normalization does not affect qualitatively the comparative statics results below. As a result, equation (27) is equivalent to:

$$
x_{f}^{*}=\frac{y_{c}+y_{s}}{t}-\frac{1}{t} \log \left[\frac{\phi_{\theta} \exp \left(2 y_{c}\right)+\exp \left(2 y_{s}\right)}{\phi_{\theta}+1+t N}\right]
$$

Similarly, in order to express $\widetilde{x}^{*}$ in terms of the ratio $\phi_{\theta} \equiv\left(1+\theta_{s}\right) /\left(1+\theta_{c}\right)$, we use the same normalization: $R_{A}=1 /\left(1+\theta_{c}\right)$. Thus, equation $(28)$ can be written as:

$$
\widetilde{x}^{*}=\frac{y_{c}}{t}+\frac{1}{2 t}\left[\log \left\{\frac{\phi_{\theta} \exp \left(2 y_{c}\right)+\exp \left(2 y_{s}\right)}{\phi_{\theta}+1+t N}\right\}\right]
$$

By totally differentiating (48), it is straightforward to show that:

$$
\begin{gathered}
\frac{\partial x_{f}^{*}}{\partial \phi_{\theta}} \gtreqless 0 \Leftrightarrow y_{s}-y_{c} \gtreqless \frac{1}{2} \log (1+t N) \\
\frac{\partial x_{f}^{*}}{\partial N}>0 \\
\frac{\partial x_{f}^{*}}{\partial y_{c}} \gtreqless 0 \Leftrightarrow y_{s}-y_{c} \gtreqless \frac{1}{2} \log \phi_{\theta} \\
\frac{\partial x_{f}^{*}}{\partial y_{s}} \gtreqless 0 \Leftrightarrow y_{s}-y_{c} \lesseqgtr \frac{1}{2} \log \phi_{\theta} \\
\frac{\partial x_{f}^{*}}{\partial t} \gtreqless 0 \Leftrightarrow y_{s}+y_{c} \lesseqgtr \frac{t N}{\phi_{\theta}+1+t N}+\log \left[\frac{\phi_{\theta} \exp \left(2 y_{c}\right)+\exp \left(2 y_{s}\right)}{\phi_{\theta}+1+t N}\right]
\end{gathered}
$$

Also, by totally differentiating (49), it can be shown that:

$$
\frac{\partial \widetilde{x}^{*}}{\partial \phi_{\theta}} \gtreqless 0 \Leftrightarrow \exp \left[2\left(y_{s}-y_{c}\right)\right] \lesseqgtr 1+t N
$$




\section{Appendix 2. The case of two spatially isolated cities that compete for their labor force}

Imagine that there is no spatial interaction between the CBD and the SBD so that we have in fact two cities who are juxtaposed, as described by Figure A.1. To be more precise, let us consider two spatially isolated business districts (the CBD and the SBD) which workers can move between costlessly (with a perfectly elastic demand for labor at wage $y_{s}$ and $y_{c}$ ) and where utility achieved in both locations is fixed at $u^{*}$. In that case, the equilibrium cannot be anymore defined as in Definition 1 but as follows.

Definition 2 An urban land-use equilibrium in a two-separated city framework with freemobility between them is a vector $\left(u, x_{f}^{c}, x_{f}^{s}, N_{c}, N_{s}\right)$ such that:

$$
\begin{gathered}
R\left(x_{f}^{c}, u, \theta_{c}\right)=R_{A} \\
\int_{0}^{x_{f}^{c}} \frac{h_{c}\left(S_{c}\right)}{q_{c}(x, u)} d x=N_{c} \\
R\left(x_{f}^{s}, u, \theta_{s}\right)=R_{A} \\
\int_{0}^{x_{f}^{s}} \frac{h_{s}\left(S_{s}\right)}{q_{s}(x, u)} d x=N_{s} \\
u_{c}=u_{s}=u^{*} \\
N=N_{s}+N_{f}
\end{gathered}
$$

We have the following result:

Proposition 3 Consider two adjacent (linear and closed) cities with free-mobility of labor between them. If the utility function is quasi-linear and defined as in (7), the production function $h(S)$ is Cobb-Douglas as in (1), then we obtain the following equilibrium values:

$$
\begin{gathered}
x_{f}^{c *}=\frac{1}{2 t} \log \left[1+\frac{\left(1+\theta_{s}\right)\left[t N+\left(1+\theta_{s}\right) R_{A}\right] \exp \left[2\left(y_{c}-y_{s}\right)\right]-\left(1+\theta_{c}\right)^{2} R_{A}}{\left(1+\theta_{c}\right)^{2} R_{A}+\left(1+\theta_{s}\right)\left(1+\theta_{c}\right) R_{A} \exp \left[2\left(y_{c}-y_{s}\right)\right]}\right] \\
x_{f}^{s *}=\frac{1}{2 t} \log \left[1+\frac{\left(1+\theta_{c}\right)\left[t N+\left(1+\theta_{c}\right) R_{A}\right]-\left(1+\theta_{s}\right)^{2} R_{A} \exp \left[2\left(y_{c}-y_{s}\right)\right]}{\left(1+\theta_{c}\right)\left(1+\theta_{s}\right) R_{A}+\left(1+\theta_{s}\right)^{2} R_{A} \exp \left[2\left(y_{c}-y_{s}\right)\right]}\right] \\
N_{c}^{*}=\frac{\left(1+\theta_{s}\right)\left[t N+\left(1+\theta_{s}\right) R_{A}\right] \exp \left[2\left(y_{c}-y_{s}\right)\right]-\left(1+\theta_{c}\right)^{2} R_{A}}{t\left(1+\theta_{c}\right)+t\left(1+\theta_{s}\right) \exp \left[2\left(y_{c}-y_{s}\right)\right]}
\end{gathered}
$$




$$
\begin{gathered}
N_{s}^{*}=\frac{t N\left(1+\theta_{c}\right)+\left(1+\theta_{c}\right)^{2} R_{A}-\left(1+\theta_{s}\right)^{2} R_{A} \exp \left[2\left(y_{c}-y_{s}\right)\right]}{t\left(1+\theta_{c}\right)+t\left(1+\theta_{s}\right) \exp \left[2\left(y_{c}-y_{s}\right)\right]} \\
u^{*}=y_{c}-1-\frac{1}{2} \log \left\{\frac{\left(1+\theta_{s}\right) r\left[\left(2+\theta_{c}+\theta_{s}\right) R_{A}+t N\right] \exp \left[2\left(y_{c}-y_{s}\right)\right]}{1+\left(1+\theta_{s}\right) /\left(1+\theta_{c}\right) \exp \left[2\left(y_{c}-y_{s}\right)\right]}\right\}
\end{gathered}
$$

Proof. Since the two cities are separated, which means that the first two equations (50) and (51) are independent of equations (52) and (53), we can solve the first four equations and obtain:

$$
\begin{gathered}
x_{f}^{c}=\frac{1}{2 t} \log \left[1+\frac{t N_{c}}{\left(1+\theta_{c}\right) R_{A}}\right] \\
u_{c}=y_{c}-1-\frac{1}{2} \log \left\{\left(1+\theta_{c}\right) r\left[\left(1+\theta_{c}\right) R_{A}+t N_{c}\right]\right\} \\
x_{f}^{s}=\frac{1}{2 t} \log \left[1+\frac{t N_{s}}{\left(1+\theta_{s}\right) R_{A}}\right] \\
u_{s}=y_{s}-1-\frac{1}{2} \log \left\{\left(1+\theta_{s}\right) r\left[\left(1+\theta_{s}\right) R_{A}+t N_{s}\right]\right\}
\end{gathered}
$$

Now solving for $u_{c}=u_{s}$ (equation (54)), we obtain:

$$
\left(\frac{1+\theta_{s}}{1+\theta_{c}}\right)\left[\left(1+\theta_{s}\right) R_{A}+t N_{s}\right] \exp \left[2\left(y_{c}-y_{s}\right)\right]=\left(1+\theta_{c}\right) R_{A}+t N_{c}
$$

Using (55), this equation can be written as:

$$
\begin{aligned}
& N_{s}^{*}=\frac{t N\left(1+\theta_{c}\right)+\left(1+\theta_{c}\right)^{2} R_{A}-\left(1+\theta_{s}\right)^{2} R_{A} \exp \left[2\left(y_{c}-y_{s}\right)\right]}{t\left(1+\theta_{c}\right)+t\left(1+\theta_{s}\right) \exp \left[2\left(y_{c}-y_{s}\right)\right]} \\
& N_{c}^{*}=\frac{\left(1+\theta_{s}\right)\left[t N+\left(1+\theta_{s}\right) R_{A}\right] \exp \left[2\left(y_{c}-y_{s}\right)\right]-\left(1+\theta_{c}\right)^{2} R_{A}}{t\left(1+\theta_{c}\right)+t\left(1+\theta_{s}\right) \exp \left[2\left(y_{c}-y_{s}\right)\right]}
\end{aligned}
$$

which are (59) and (58), respectively. By plugging these values in (61) and (63), we obtain:

$$
\begin{aligned}
& x_{f}^{c *}=\frac{1}{2 t} \log \left[1+\frac{\left(1+\theta_{s}\right)\left[t N+\left(1+\theta_{s}\right) R_{A}\right] \exp \left[2\left(y_{c}-y_{s}\right)\right]-\left(1+\theta_{c}\right)^{2} R_{A}}{\left(1+\theta_{c}\right)^{2} R_{A}+\left(1+\theta_{s}\right)\left(1+\theta_{c}\right) R_{A} \exp \left[2\left(y_{c}-y_{s}\right)\right]}\right] \\
& x_{f}^{s *}=\frac{1}{2 t} \log \left[1+\frac{\left(1+\theta_{c}\right)\left[t N+\left(1+\theta_{c}\right) R_{A}\right]-\left(1+\theta_{s}\right)^{2} R_{A} \exp \left[2\left(y_{c}-y_{s}\right)\right]}{\left(1+\theta_{c}\right)\left(1+\theta_{s}\right) R_{A}+\left(1+\theta_{s}\right)\left(1+\theta_{s}\right) R_{A} \exp \left[2\left(y_{c}-y_{s}\right)\right]}\right]
\end{aligned}
$$

which are (56) and (57), respectively.

Finally, by plugging the value of $N_{c}$ from (58) into (62), we obtain:

$$
u^{*}=y_{c}-1-\frac{1}{2} \log \left\{\frac{\left(1+\theta_{s}\right) r\left[\left(2+\theta_{c}+\theta_{s}\right) R_{A}+t N\right] \exp \left[2\left(y_{c}-y_{s}\right)\right]}{1+\left(1+\theta_{s}\right) /\left(1+\theta_{c}\right) \exp \left[2\left(y_{c}-y_{s}\right)\right]}\right\}
$$


which is (60).

Observe that, since the utility is the same everywhere in each city, then equation (54) has to be true at each city fringe $x_{f}^{c}$ and $x_{f}^{s}$ where $R_{H}\left(x_{f}^{c}\right)=R_{H}\left(x_{f}^{s}\right)=R_{A}$. As a result, $u_{c}=u_{s}$ is equivalent to:

$$
\begin{gathered}
y_{c}-t x_{f}^{c}-1-\log R_{A}=y_{s}-t x_{f}^{s}-1-\log R_{A} \\
\Leftrightarrow x_{f}^{c}-x_{f}^{s}=\frac{y_{c}-y_{s}}{t}
\end{gathered}
$$

Denote by

$$
\phi_{\theta} \equiv \frac{1+\theta_{s}}{1+\theta_{c}}
$$

the ratio between the property tax in the suburbs and in the center.

Proposition 4 An increase in the property tax ratio between the suburbs and the city-center, $\phi_{\theta} \equiv\left(1+\theta_{s}\right) /\left(1+\theta_{c}\right)$, increases the urban sprawl in the central city but decreases it in the other city, i.e.

$$
\frac{\partial x_{f}^{c *}}{\partial \phi_{\theta}}>0 \text { and } \frac{\partial x_{f}^{s *}}{\partial \phi_{\theta}}<0
$$

This means, in particular, that

$$
\frac{\partial x_{f}^{c *}}{\partial \theta_{c}}<0 \text { and } \frac{\partial x_{f}^{s *}}{\partial \theta_{s}}<0
$$

Proof. Normalize $R_{A} \equiv 1 /\left(1+\theta_{c}\right)$. Then (56) can be written as:

$$
x_{f}^{c *}=\frac{1}{2 t} \log \left[1+\frac{\phi_{\theta}\left[t N+\phi_{\theta}\right] \exp \left[2\left(y_{c}-y_{s}\right)\right]-1}{1+\phi_{\theta} \exp \left[2\left(y_{c}-y_{s}\right)\right]}\right]
$$

It easily seen that:

$$
\operatorname{sgn}\left[\frac{\partial x_{f}^{c *}}{\partial \phi_{\theta}}\right]=\operatorname{sgn}\left[\frac{\partial\left[\frac{\phi_{\theta}\left[t N+\phi_{\theta}\right] \exp \left[2\left(y_{c}-y_{s}\right)\right]-1}{1+\phi_{\theta} \exp \left[2\left(y_{c}-y_{s}\right)\right]}\right]}{\partial \phi_{\theta}}\right]
$$

where

$$
\begin{aligned}
& \frac{\partial\left[\frac{\phi_{\theta}\left[t N+\phi_{\theta}\right] \exp \left[2\left(y_{c}-y_{s}\right)\right]-1}{1+\phi_{\theta} \exp \left[2\left(y_{c}-y_{s}\right)\right]}\right]}{\partial \phi_{\theta}} \\
= & \exp \left[2\left(y_{c}-y_{s}\right)\right]\left\{\frac{t N+2 \phi_{\theta}+\phi_{\theta} \exp \left[2\left(y_{c}-y_{s}\right)\right] \phi_{\theta}+1}{\left(1+\phi_{\theta} \exp \left[2\left(y_{c}-y_{s}\right)\right]\right)^{2}}\right\}>0
\end{aligned}
$$


Similarly, by normalizing $R_{A} \equiv 1 /\left(1+\theta_{c}\right),(57)$ can be written as:

$$
\begin{aligned}
x_{f}^{s *} & =\frac{1}{2 t} \log \left[1+\frac{\left(1+\theta_{c}\right) t N+\left(1+\theta_{c}\right)-\left(1+\theta_{s}\right)^{2} /\left(1+\theta_{c}\right) \exp \left[2\left(y_{c}-y_{s}\right)\right]}{\left(1+\theta_{s}\right)+\left(1+\theta_{s}\right)^{2} /\left(1+\theta_{c}\right) \exp \left[2\left(y_{c}-y_{s}\right)\right]}\right] \\
& =\frac{1}{2 t} \log \left[1+\frac{t N+1-\phi_{\theta}^{2} \exp \left[2\left(y_{c}-y_{s}\right)\right]}{\phi_{\theta}+\phi_{\theta}^{2} \exp \left[2\left(y_{c}-y_{s}\right)\right]}\right]
\end{aligned}
$$

It easily seen that:

$$
\operatorname{sgn}\left[\frac{\partial x_{f}^{s *}}{\partial \phi_{\theta}}\right]=\operatorname{sgn}\left[\frac{\partial\left[\frac{t N+1-\phi_{\theta}^{2} \exp \left[2\left(y_{c}-y_{s}\right)\right]}{\phi_{\theta}+\phi_{\theta}^{2} \exp \left[2\left(y_{c}-y_{s}\right)\right]}\right]}{\partial \phi_{\theta}}\right]
$$

where

$$
\begin{aligned}
& \frac{\partial\left[\frac{t N+1-\phi_{\theta}^{2} \exp \left[2\left(y_{c}-y_{s}\right)\right]}{\phi_{\theta}+\phi_{\theta}^{2} \exp \left[2\left(y_{c}-y_{s}\right)\right]}\right]}{\partial \phi_{\theta}} \\
= & \frac{-\phi_{\theta}^{2} \exp \left[2\left(y_{c}-y_{s}\right)\right]-(t N+1)-(t N+1) 2 \phi_{\theta} \exp \left[2\left(y_{c}-y_{s}\right)\right]}{\left(\phi_{\theta}+\phi_{\theta}^{2} \exp \left[2\left(y_{c}-y_{s}\right)\right]\right)^{2}}<0
\end{aligned}
$$




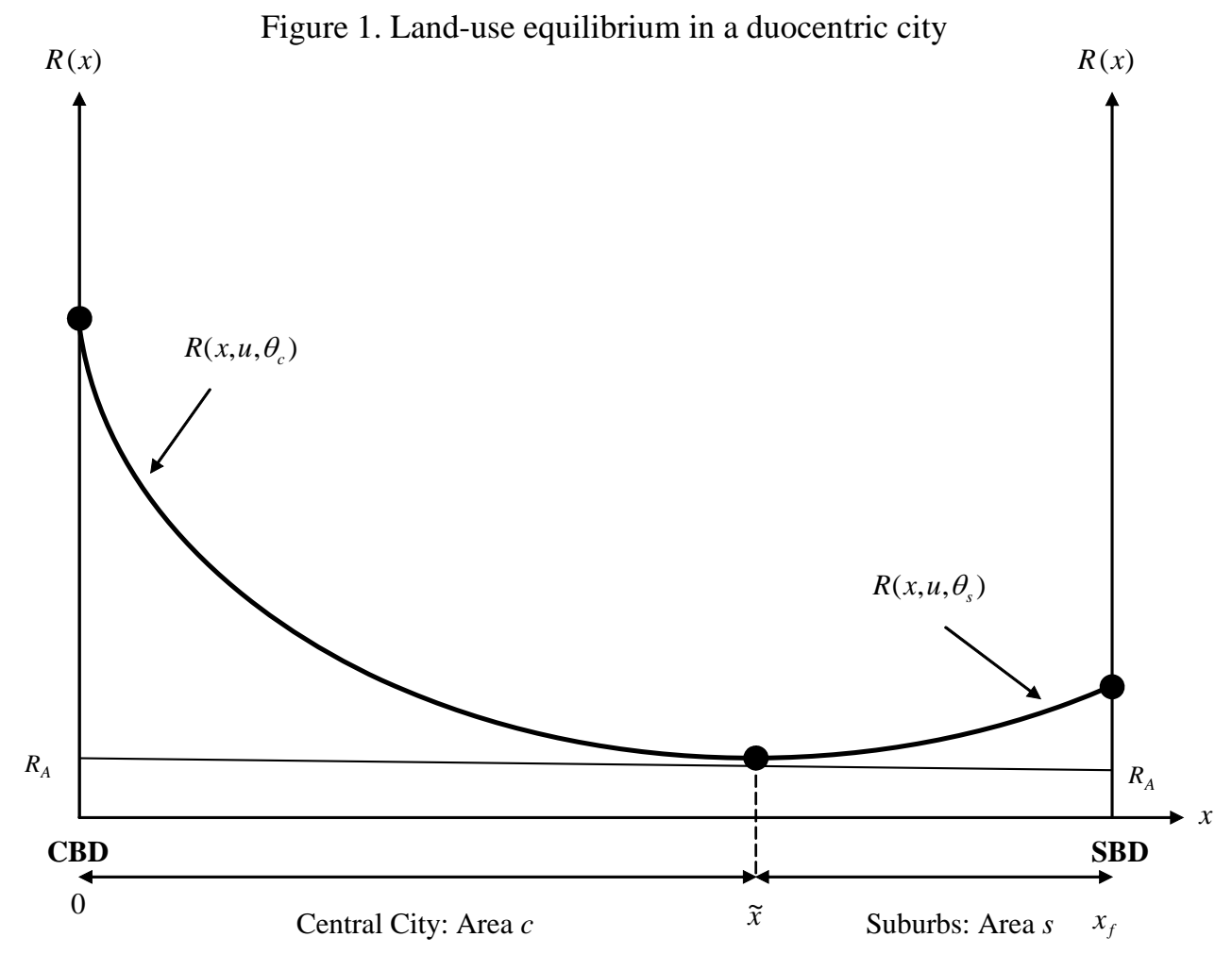


Figure 2. Effect of an increase in $\theta_{s}$ holding $\widetilde{x}$ constant

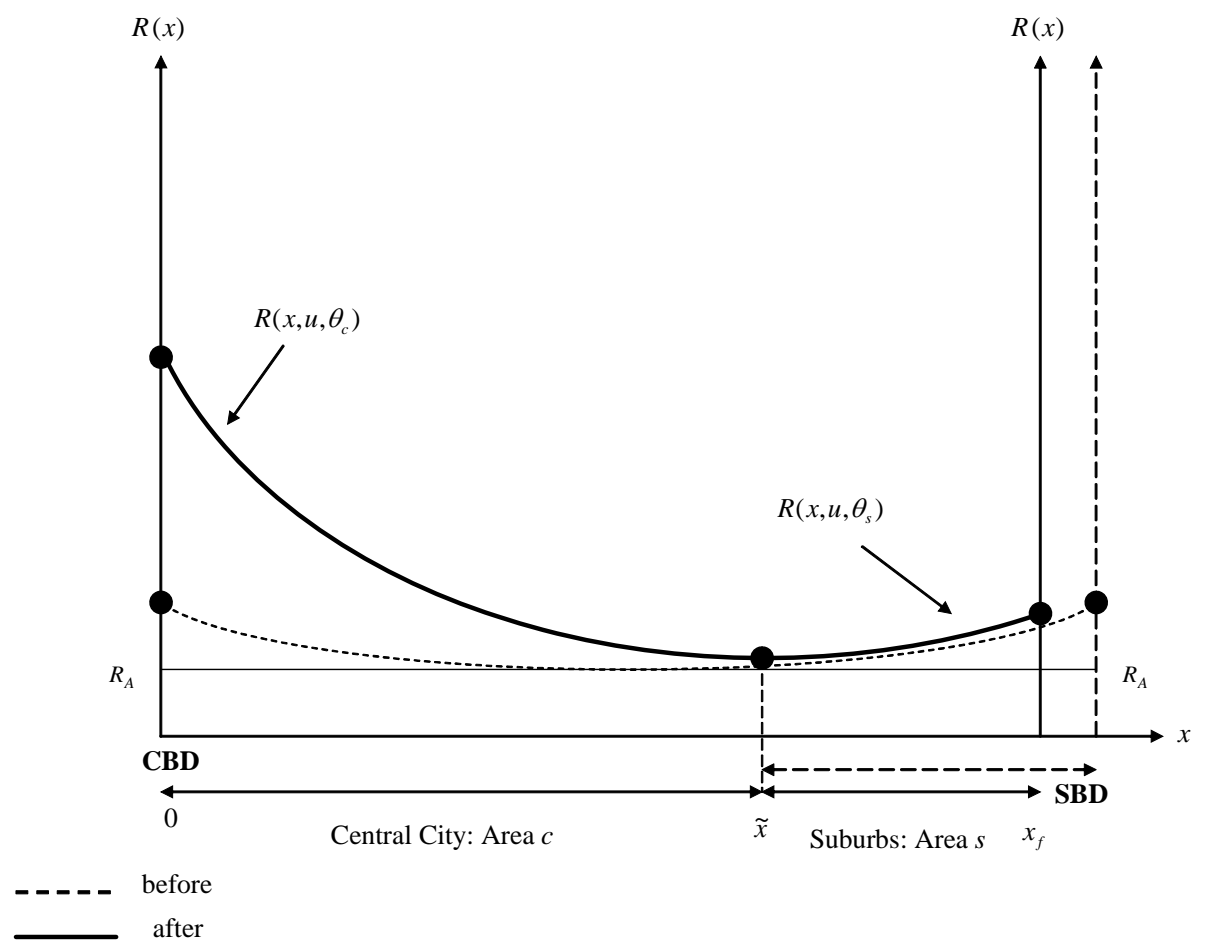




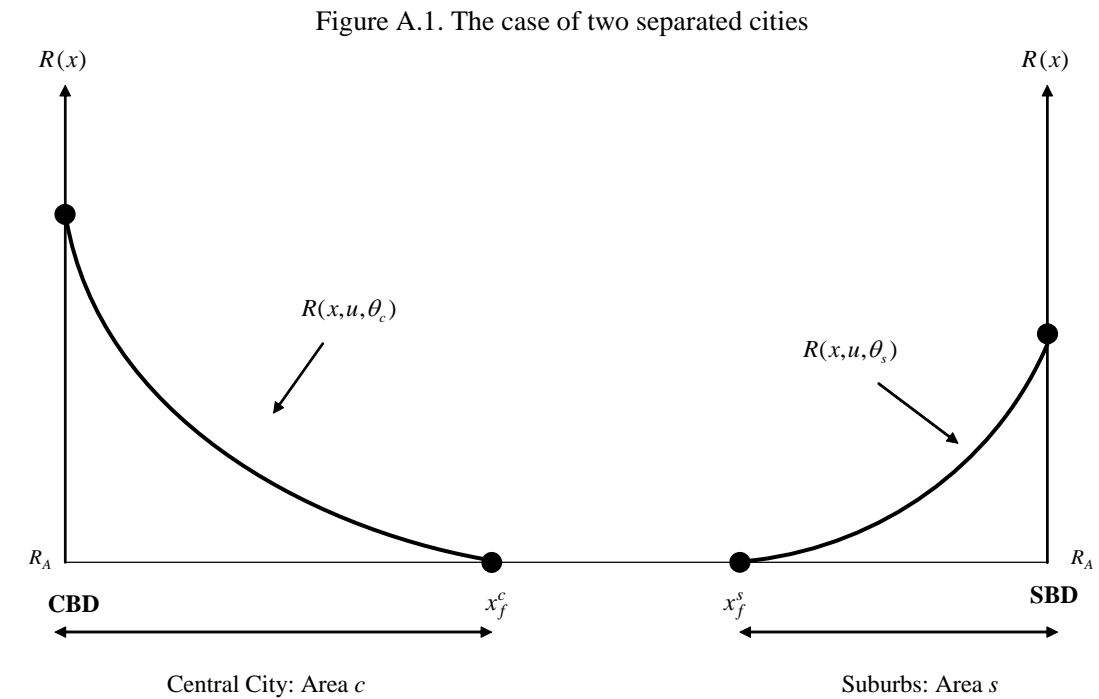


Figure 3. Levels of taxation in the Central Place of Salem Urbanized Area, OR

\section{Layer 1 - Aggregated County tax millage rate: 4.26}

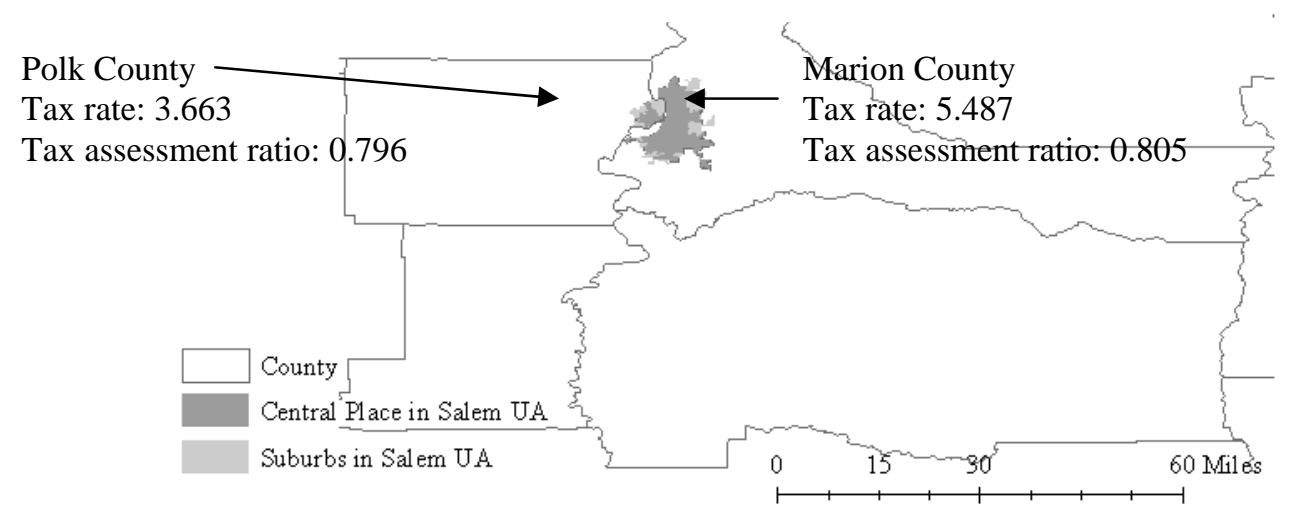

\section{Layer 2 - Aggregated City} tax millage rate: 5.20

Keizer:

Tax rate: 3.629

Tax assessment ratio: 0.805
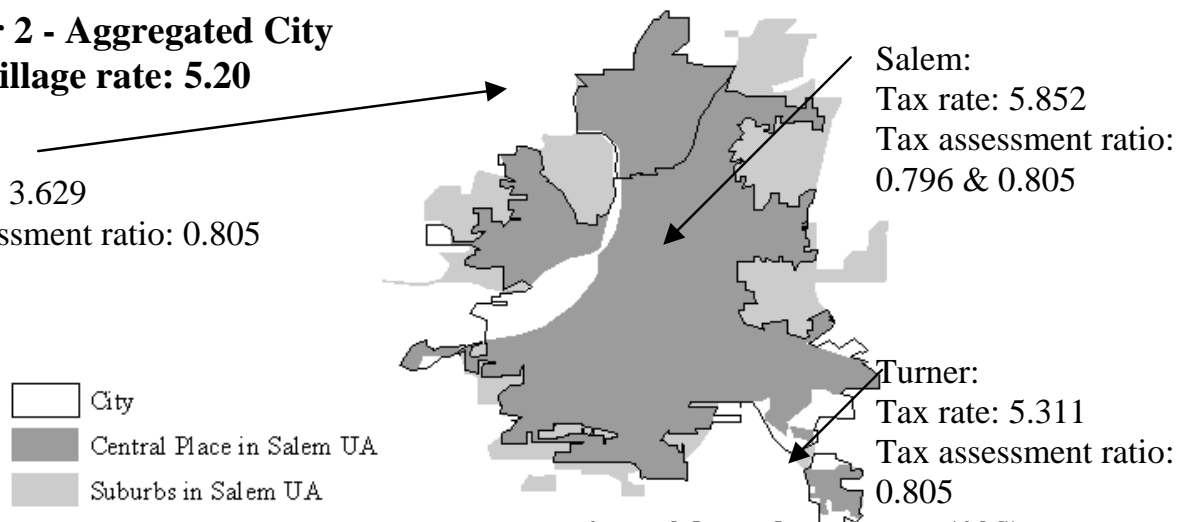

Layer 3 - Aggregated School district tax millage rate: $\mathbf{5 . 3 1}$

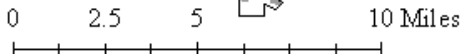

$$
\Gamma^{-}
$$

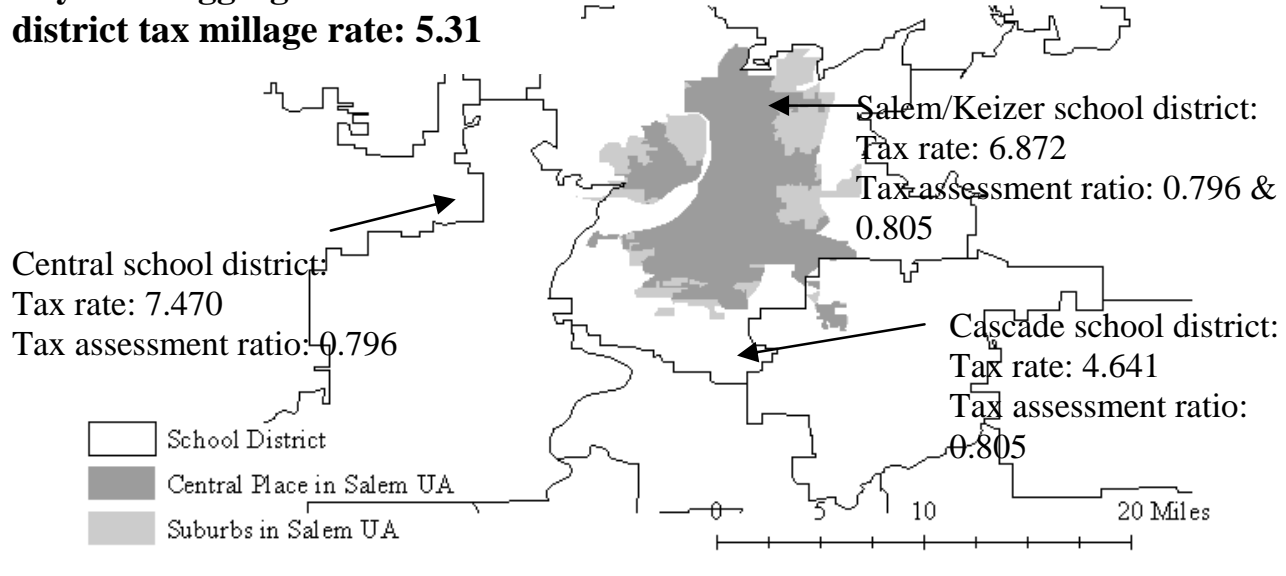

Central school district

Tax rate: 7.470

Tax assessment ratio: $\Theta .796$
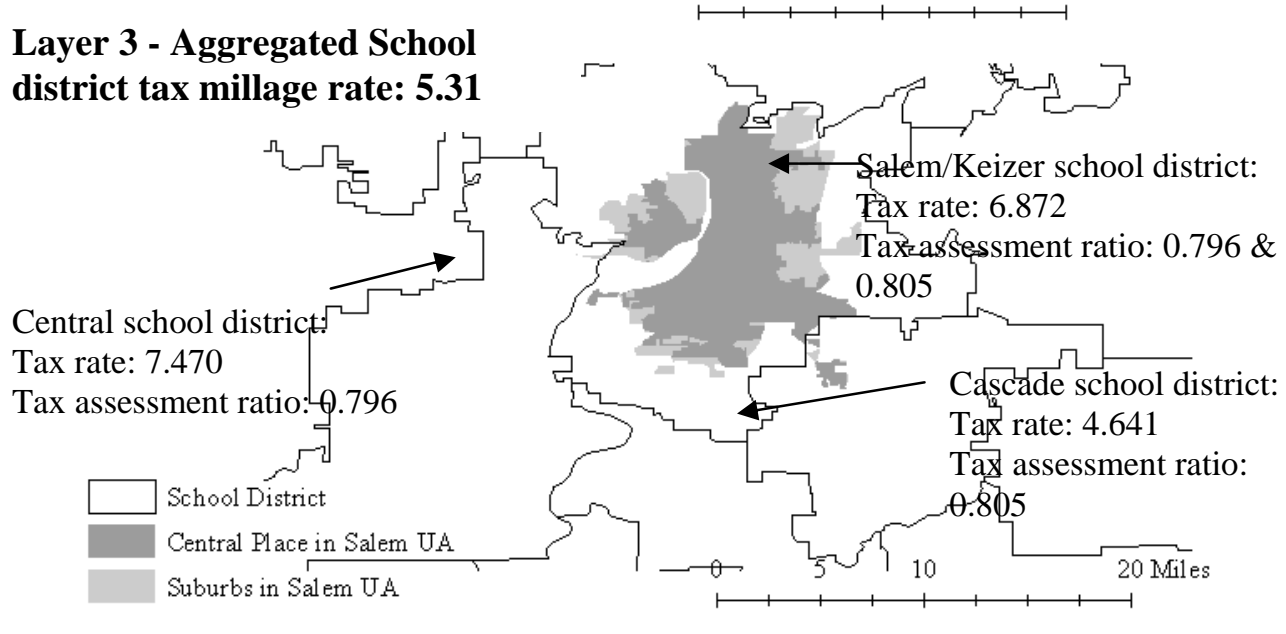
Table 1. Dependent and Independent Variables and Measurements

\begin{tabular}{|c|c|}
\hline Variables & Measurements (Data Source) \\
\hline \multicolumn{2}{|l|}{ Dependent Variables } \\
\hline Urban scale & $\begin{array}{l}\text { The spatial extent of land area in the urbanized area in } \\
\text { acres in } 2000 \text { (U.S. Census). }\end{array}$ \\
\hline Population decentralization & $\begin{array}{l}\text { A two-point (the central city vs. the suburbs) estimation } \\
\text { of population density gradient (2000 U.S. census and } \\
\text { numeric computation). }\end{array}$ \\
\hline Employment decentralization & $\begin{array}{l}\text { A two-point (the central city vs. the suburbs) estimation } \\
\text { of employment density gradient ( } 2000 \text { U.S. census and } \\
\text { numeric computation). }\end{array}$ \\
\hline \multicolumn{2}{|l|}{ Independent Variables } \\
\hline Urbanized area population & 2000 Urbanized area population (U.S. Census). \\
\hline Income & $\begin{array}{l}\text { Simulated income based on a combination of } \\
\text { employment shares for each urbanized area and skill } \\
\text { prices (U.S. Census). }\end{array}$ \\
\hline Agricultural land rent & $\begin{array}{l}\text { Weighted average of median agricultural land value per } \\
\text { acre in the urbanized area in } 1997 \text { (U.S. Census of } \\
\text { Agriculture/National Agricultural Statistics Service and } \\
\text { GIS operation). }\end{array}$ \\
\hline Highway lane miles & $\begin{array}{l}\text { Highway lane miles in the urbanized area in } 2000 \text { (U.S. } \\
\text { GIS Data Depot and GIS operation). }\end{array}$ \\
\hline Transit & $\begin{array}{l}\text { Number of commuters using public transit in } 2000 \text { (U.S. } \\
\text { Census). }\end{array}$ \\
\hline Auto & Number of commuters using automobiles (U.S. Census). \\
\hline Climate & $\begin{array}{l}\text { Nine intervals indicating the annual mean daily average } \\
\text { temperature in the urbanized area, with } 1=<32,2=32.0- \\
40.0,3=40.1-45.0,4=45.1-50.0,5=50.1-55.0,6=55.1- \\
60.0,7=60.1-65.0,8=65.1-70.0 \text {, and } 9=>70.0 \mathrm{~F} \\
\text { (National Climate Data Center). }\end{array}$ \\
\hline $\begin{array}{l}\text { Share of employment in } \\
\text { services }\end{array}$ & $\begin{array}{l}\text { The share of labor force in services in } 2000 \text { (U.S. } \\
\text { Census). }\end{array}$ \\
\hline Crime rate & $\begin{array}{l}\text { Crime rate of serious crimes (offenses per 100,000 } \\
\text { inhabitants) known to police in the central city in } 1999 \\
\text { ( } 2000 \text { County and City Data Books: } 2000 \text { City Files). }\end{array}$ \\
\hline $\begin{array}{l}\text { Ratio of property tax rates } \\
\text { between suburbs and central } \\
\text { city }\end{array}$ & $\begin{array}{l}\text { Ratio of weighted average property tax millage rates } \\
\text { between suburbs and central city in } 1997 \text { (U.S. Census, } \\
\text { Web survey, Secondary Data sources and GIS operation). }\end{array}$ \\
\hline
\end{tabular}


Table 2. Descriptive Statistics

\begin{tabular}{|l|r|r|r|r|}
\hline \multicolumn{1}{|c|}{ Variable } & \multicolumn{1}{c|}{ Min } & \multicolumn{1}{c|}{ Max } & \multicolumn{1}{c|}{ Mean } & Std. Dev. \\
\hline & & & & \\
\hline Urban scale in acres & 7741.77 & 1256051.00 & 90424.07 & 142038.60 \\
\hline Population density gradient & 0.001 & 2.93 & 0.47 & 0.40 \\
\hline Employment density gradient & 0.002 & 2.70 & 0.45 & 0.40 \\
\hline Population & 49776.00 & 4918839.00 & 333990.00 & 635903.30 \\
\hline Adjusted income & 15930.83 & 86571.27 & 48557.76 & 11190.51 \\
\hline Highway lane miles & 0.00 & 216.37 & 13.84 & 25.34 \\
\hline Transit & 12.00 & 275053.00 & 5661.62 & 23144.97 \\
\hline Auto & 12695.00 & 1886191.00 & 136704.10 & 260708.20 \\
\hline Agricultural land value & 0.00 & 224006.60 & 1423.53 & 10978.55 \\
\hline Climate (9 intervals) & 2.05 & 9.00 & 5.82 & 1.63 \\
\hline Share of employment in services & 0.15 & 0.57 & 0.27 & 0.05 \\
\hline Crime rate & 998 & 22,078 & 5124.93 & 2468.34 \\
\hline Ratio of property tax rates & 0.47 & 1.58 & 0.91 & 0.15 \\
\hline
\end{tabular}


Table 3. Regression Results

\begin{tabular}{|c|c|c|c|c|c|c|}
\hline & (1) IV & (2) OLS & (3) OLS & (4) IV & (5) OLS & (6) OLS \\
\hline Dependent Variable & Urban Scale & Urban Scale & Urban Scale & Urban Scale & $\begin{array}{c}\text { Population } \\
\text { Decentralization }\end{array}$ & $\begin{array}{c}\text { Employment } \\
\text { Decentralization }\end{array}$ \\
\hline \multirow[t]{2}{*}{ Population } & 0.00014 & 0.00020 & 0.00021 & 0.00013 & 0.00000 & 0.00000 \\
\hline & $(0.0000) * * *$ & $(0.0000) * * *$ & $(0.0000) * * *$ & $(0.0000) * * *$ & $(0.0000)$ & $(0.0000)$ \\
\hline \multirow[t]{2}{*}{ Adjusted income } & 0.00089 & 0.00085 & 0.00105 & 0.00074 & -0.00000 & -0.00001 \\
\hline & $(0.0003) * * *$ & $(0.0003) * * *$ & $(0.0003)^{* * *}$ & $(0.0003)^{* * *}$ & $(0.0000)^{* * *}$ & $(0.0000) * * *$ \\
\hline \multirow[t]{2}{*}{ Agricultural land rent } & -0.00060 & -0.00044 & -0.00033 & -0.00055 & 0.00000 & 0.00000 \\
\hline & $(0.0003)^{*}$ & $(0.0005)$ & $(0.0003)$ & $(0.0003)^{*}$ & $(0.0000)^{*}$ & $(0.0000)^{*}$ \\
\hline \multirow[t]{2}{*}{ Highway lane miles } & 2.49127 & & & 2.62406 & -0.00395 & -0.00431 \\
\hline & $(0.2589) * * *$ & & & $(0.2609)^{* * *}$ & $(0.0010)^{* * *}$ & $(0.0010) * * *$ \\
\hline \multirow[t]{2}{*}{ Transit } & & -0.00139 & & & & \\
\hline & & $(0.0002) * * *$ & & & & \\
\hline \multirow[t]{2}{*}{ Auto } & & & 0.00003 & & & \\
\hline & & & $(0.0001)$ & & & \\
\hline \multirow[t]{2}{*}{ Climate } & & & & 4.40688 & -0.02691 & -0.02243 \\
\hline & & & & $(1.8832)^{* *}$ & $(0.0071)^{* * *}$ & $(0.0072)^{* * *}$ \\
\hline \multirow[t]{2}{*}{ Employment in services } & & & & -142.39990 & 0.67225 & 0.59202 \\
\hline & & & & $(59.0990)^{* *}$ & $(0.2230)^{* * *}$ & $(0.2270) * * *$ \\
\hline \multirow[t]{2}{*}{ Crime rate in central city } & & & & & -0.00076 & -0.00055 \\
\hline & & & & & $(0.0007)$ & $(0.0005)$ \\
\hline \multirow[t]{2}{*}{ Ratio of property tax rates } & -45.36870 & -42.71145 & -38.66797 & -45.70407 & 0.27037 & 0.27680 \\
\hline & $(21.0148)^{* *}$ & $(22.2520)^{* *}$ & $(23.0827)^{* *}$ & $(20.9240)^{* *}$ & $(0.0790)^{* * *}$ & $(0.0802)^{* * *}$ \\
\hline \multirow[t]{2}{*}{ Constant } & 174.89700 & 186.45300 & 185.83940 & 195.99050 & 1.10395 & 1.14928 \\
\hline & $(24.3700)^{* * *}$ & $(25.8040) * * *$ & $(26.7810) * * *$ & $(29.8617)^{* * *}$ & $(0.1127)^{* * *}$ & $(0.1144)^{* * *}$ \\
\hline Observations & 445 & 445 & 445 & 445 & 445 & 445 \\
\hline R square & 0.84 & 0.82 & 0.80 & 0.85 & 0.27 & 0.26 \\
\hline
\end{tabular}

Notes: Standard errors are in parentheses.

* $\quad$ Significant at 10\% level; ** Significant at 5\% level; *** Significant at $1 \%$ level. 